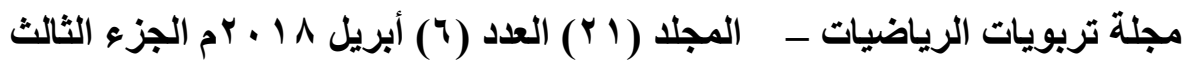

برنامج مقترح في الرياضيات الفازية ودراسة فاعليته قي تنمية التفكير

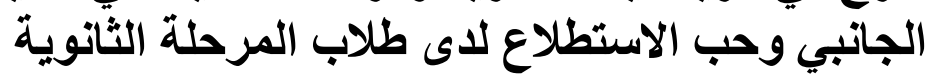

د. هبة محمد محمود عبد العال

مدرس المناهج وطرق تدريس الرياضيات مدئ مدئ

كلية التربية - جامعة عين شمس فئ الريان

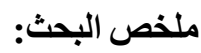




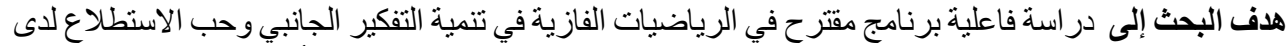

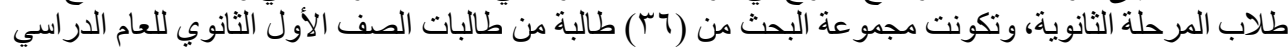

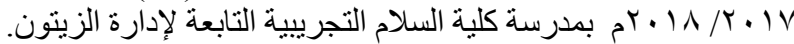
تم إعداد أدوات القياس التالية:

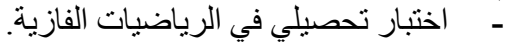

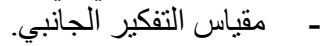

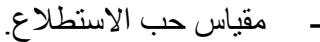

منهج البحث : هو المنهج التجريبي، وقد استخدمت الباحثة التصميم التجريبي "المجمو عة الو احدة" ذو التطبيق القبلي/

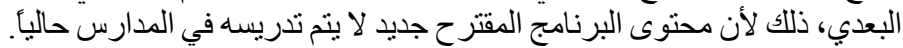

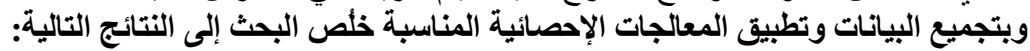

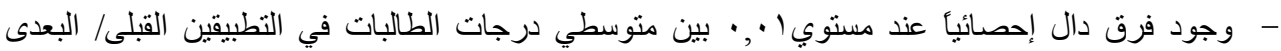
للاختبار التحصيلى لصالح التطبيق البعدي. - وجود فرق دال إحصائيا عند مستوي +., · بين منوسطي درجات الطالبات في التطبيقين القبلى/ البعدى لمقياس التفكير الجانبي لصالح التطبيق البعدي.

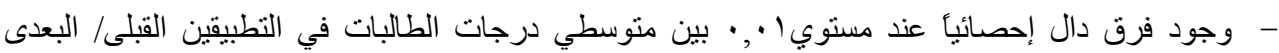

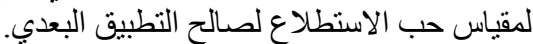

Abstract: الكلمات المفتاحية : الرياضيات الفازية ، التفكير الجانبي، حب الاستطلاع ع.

A suggested Program in Fuzzy Mathematics and His Effectiveness in developing Lateral thinking and Curiosity for The Secondary Stage Students.

The research aimed at identifying the Effectiveness of a suggested program in Fuzzy mathematics in developing lateral thinking and curiosity for the secondary stage students 'the sample consisted of (36) students from first grade secondary for academic year 2017/2018 in Al Salam College official language preparatory \& secondary stage. The research tools are Achievement test in fuzzy mathematics- Lateral thinking scale Curiosity scale.

The research methodology: The one group design is used with pre and post applied aiming to study of the effectiveness of a suggested program in the Fuzzy mathematics in developing lateral thinking and curiosity for the secondary stage students.

The research result:

- There is a statistically significant difference at the 0.01 level of significance between the means of student's degrees in the pre and post applications of Achievement test in fuzzy mathematic for the post application.

- There are statistically significant differences at the level of 0.01 between the means of student's degrees in the Pre \&post applications of lateral thinking Scale for the post application.

- There are statistically significant differences at the level of 0.01 between the means of student's degrees in the Pre \&post applications of curiosity Scale for the post application.

Key words :Fuzzy Mathematics, lateral thinking, curiosity. 


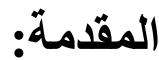

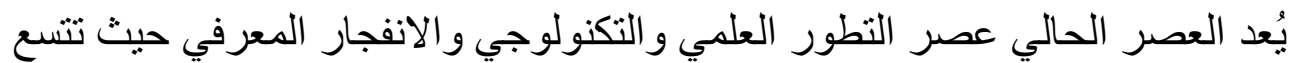

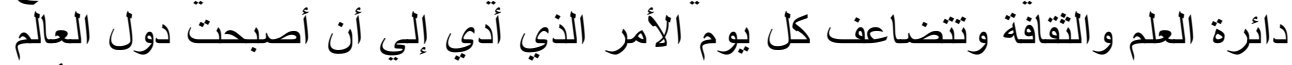

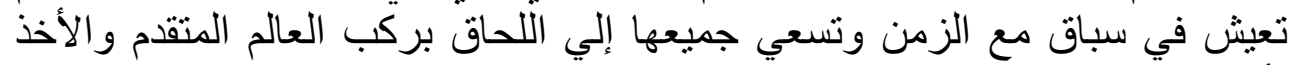

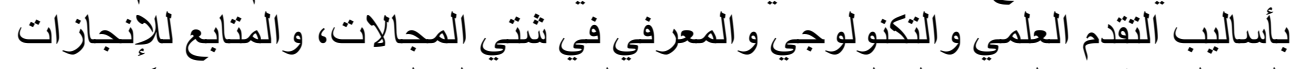

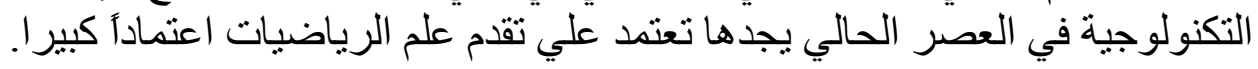

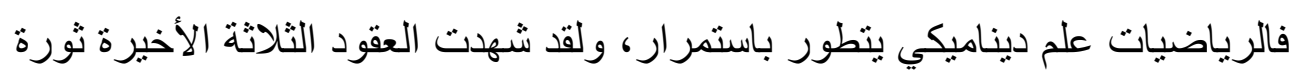

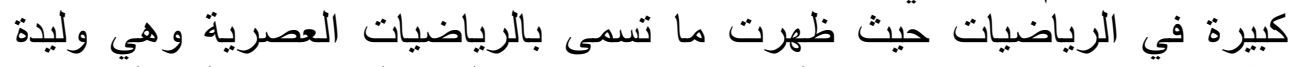

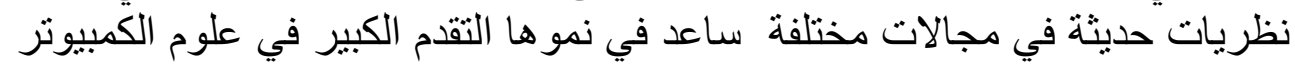

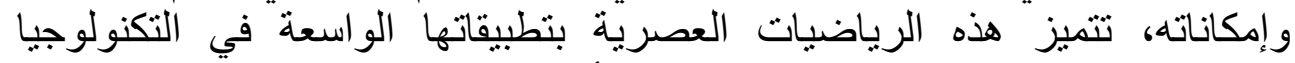

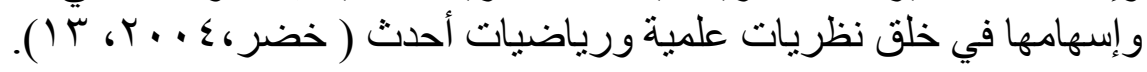

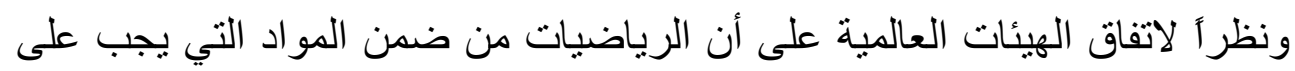

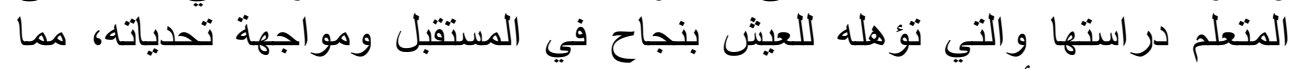

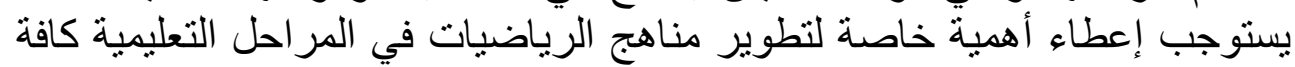

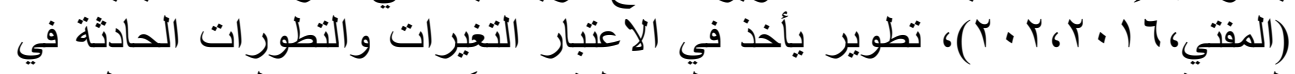

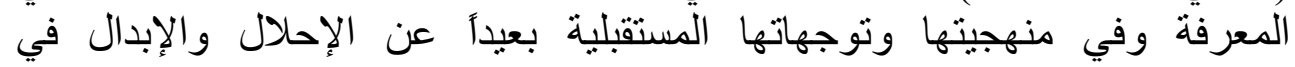

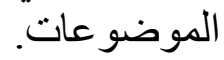

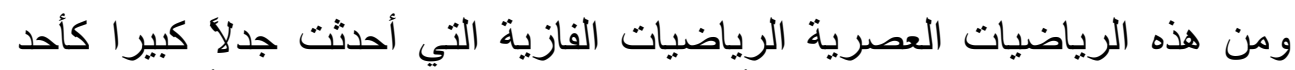

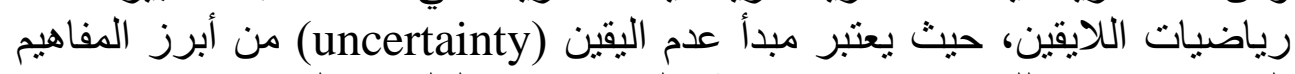

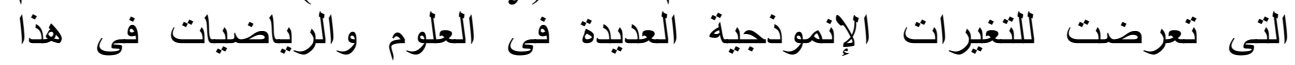

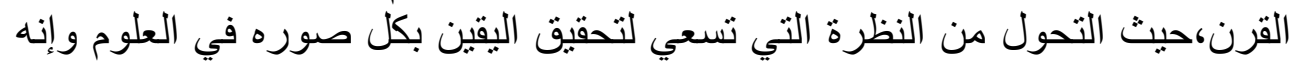

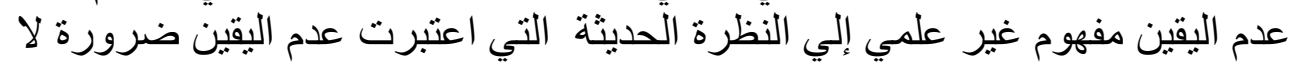
يمكن تجنبه لإهميته واستخداماته (George, M, 2006,1).

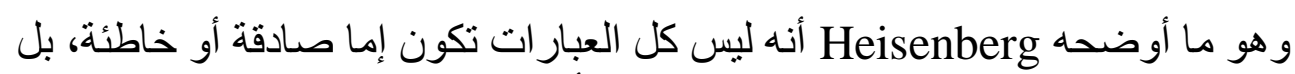

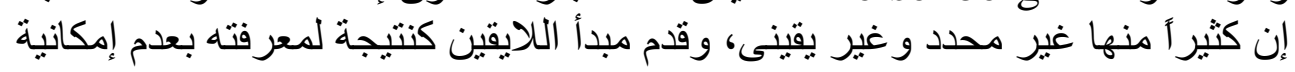

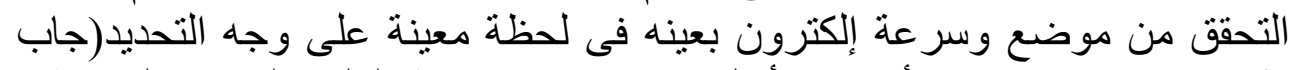

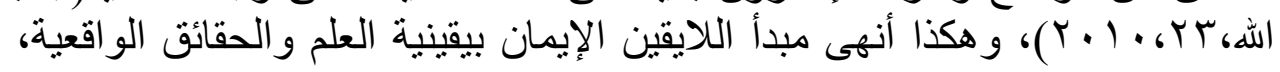

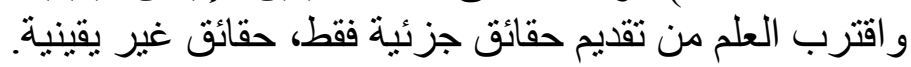




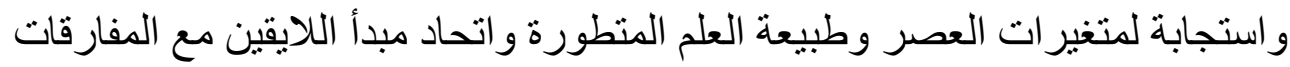

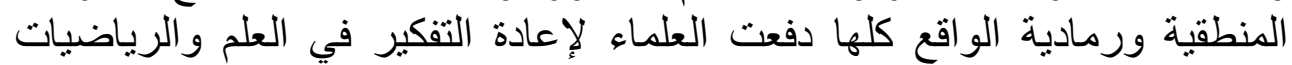

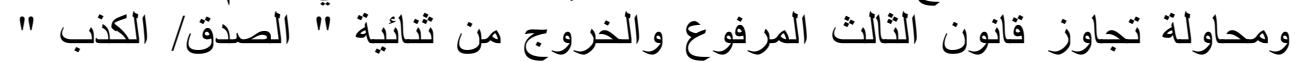

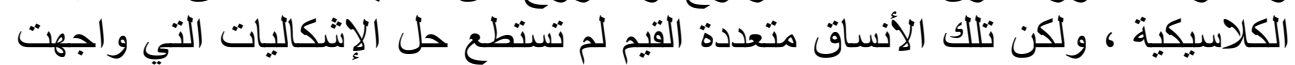

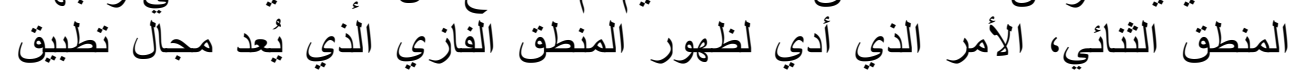

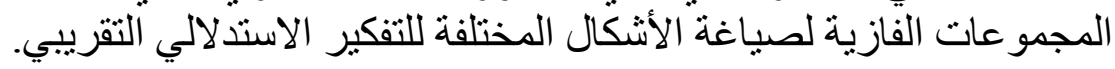
المجموعات الفازية Fuzzy sets التي قدمها لطفي زاده عام 1970 المكية كتعميم

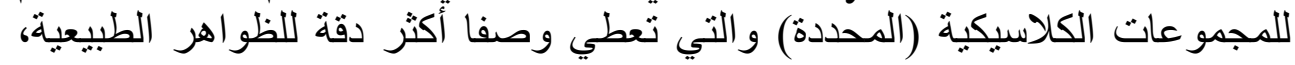

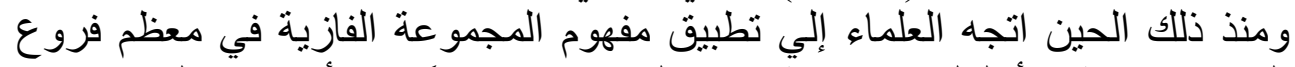

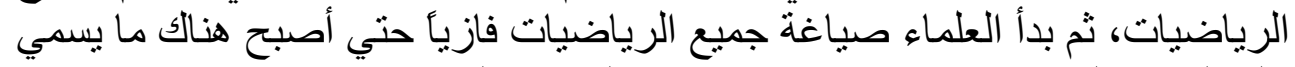

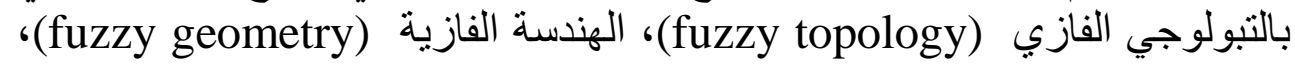

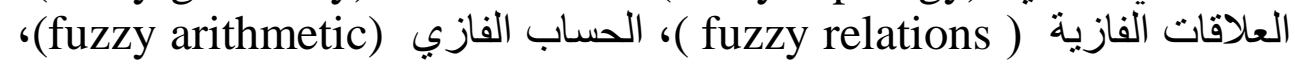
نظرية القياس الفازية (fuzzy measure theory)، التكامل الفازي ( fuzzy) (integrals و والجبر الفازي (Fuzzy algebraic). وتبرز أهمية الرياضيات الفازية في مختلف المجالات حيث يوجد إنتشار واسع الفي

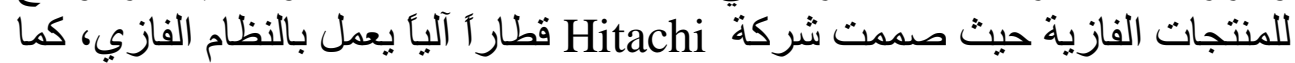
صنعت شركة Canon أول كامير ا فيديو ذات ثركيز آلي بإستعمال النظام الفازي،

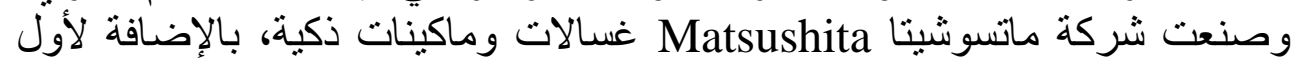
مصعد كهربائي يعمل بالنظام الفازي وكان من صناعة شركة

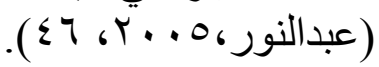

كما تعددت النجاحات التجارية لتطبيقات الأنظمة الفازية في مجالات الذكاء

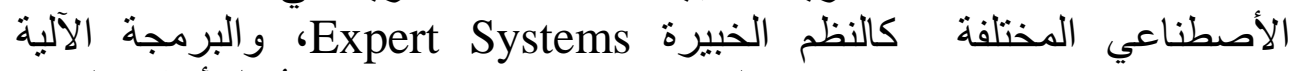

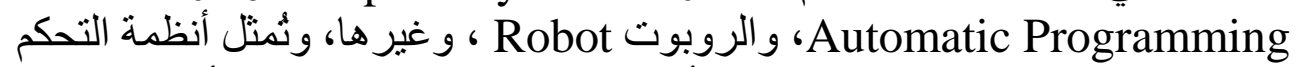
الفازية Fuzzy Control System أكبر نجاح نم إنجازه لتطبيق الأنظمة الفازية الفية في المجالات الصناعية والتجارية (Garrido.A ,2012,75).

وقد أكدت نتائج بعض البحوث والدر اسات علي ضرورة تضمين المنطق الفازى فى كي

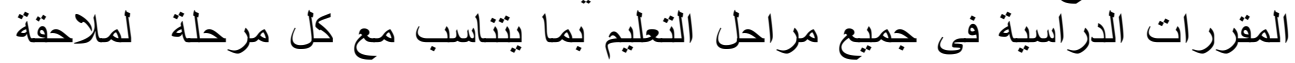

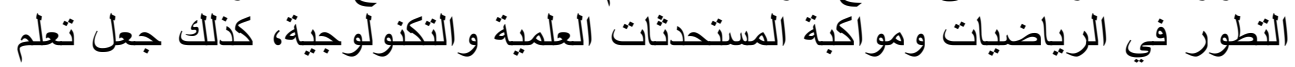

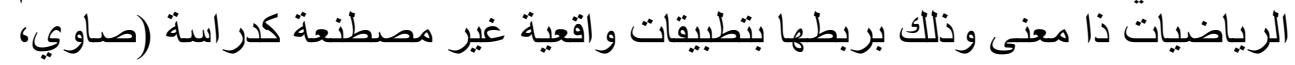

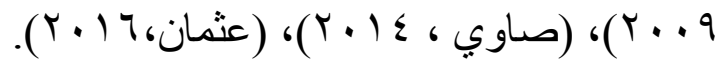




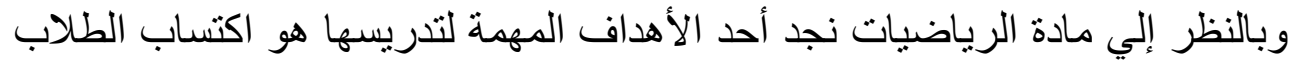

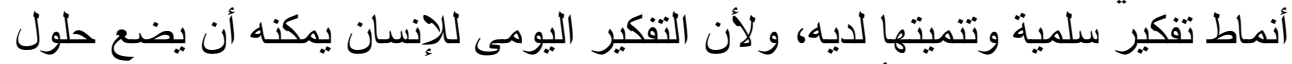

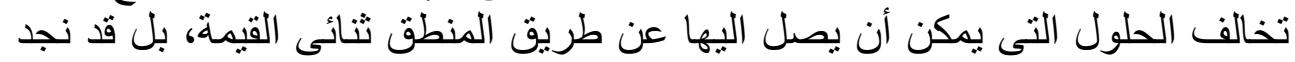

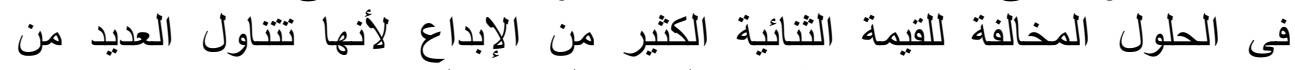

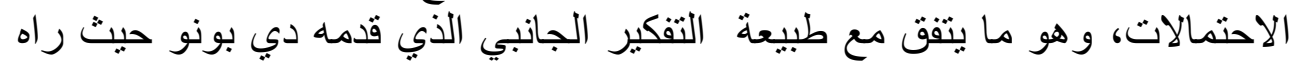

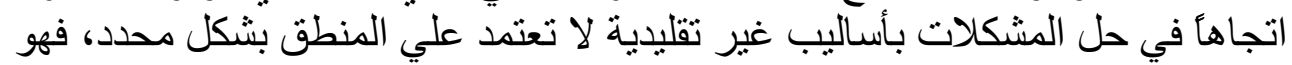

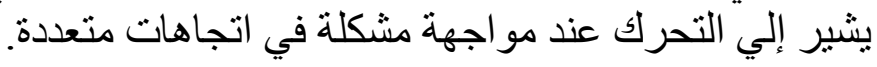

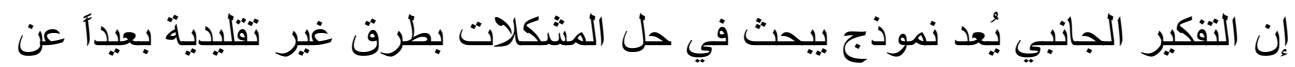

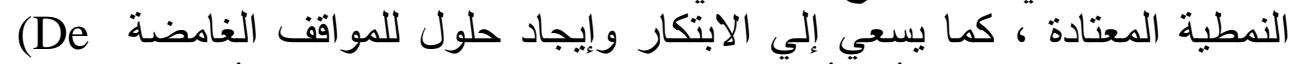

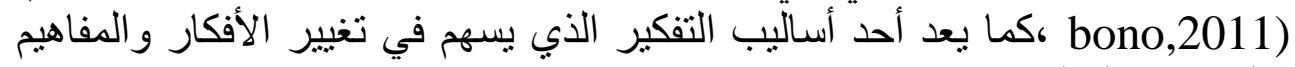

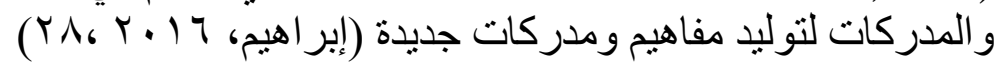

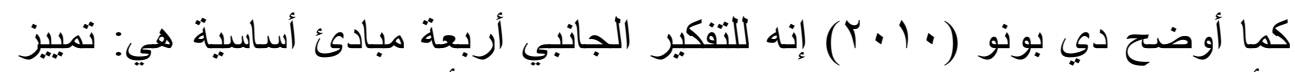

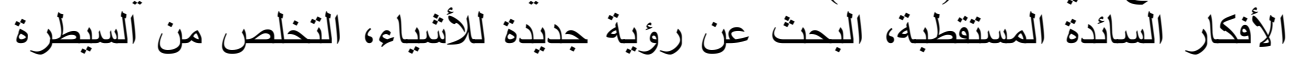

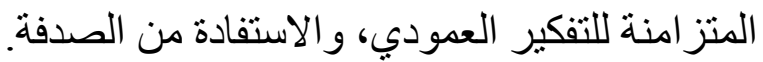

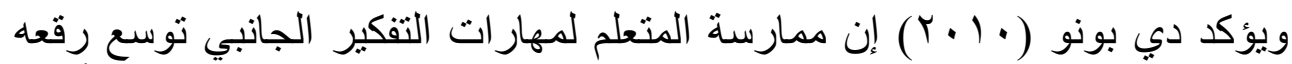

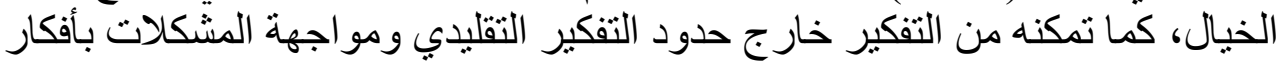

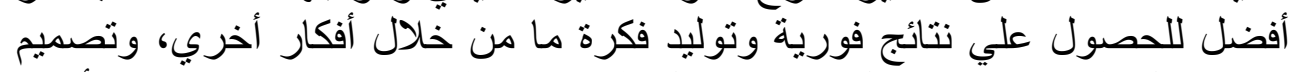

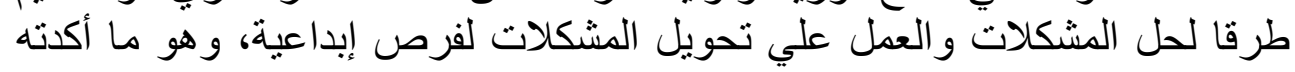

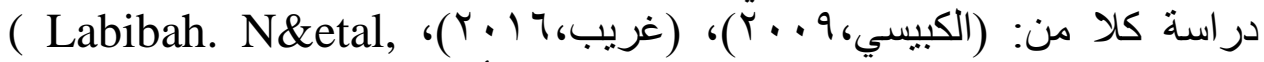
(2017) (Kumara\& Aggarwal, 2012)

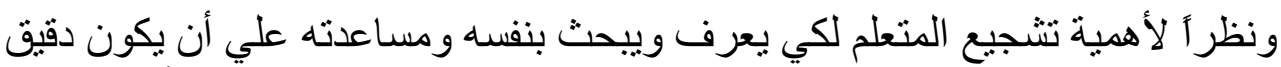

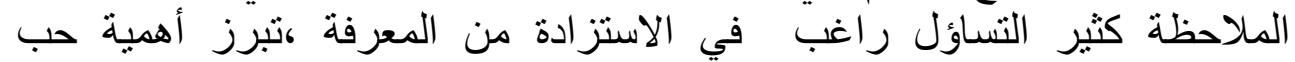

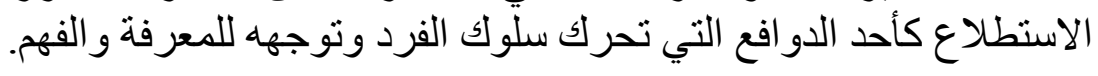

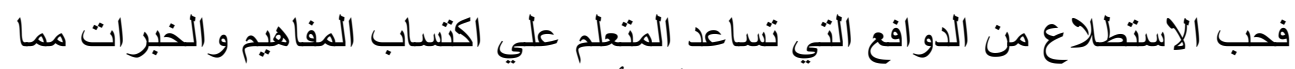

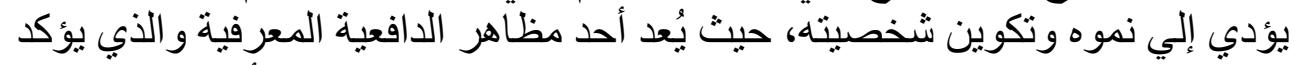

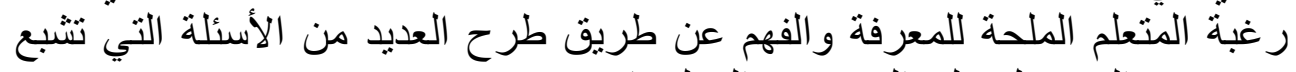
رغبته في الحصول علي المزيد من المعلومات.

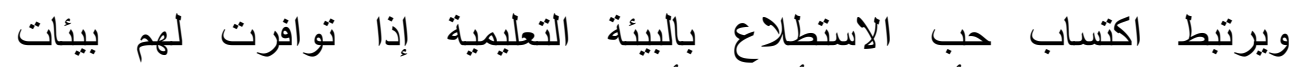

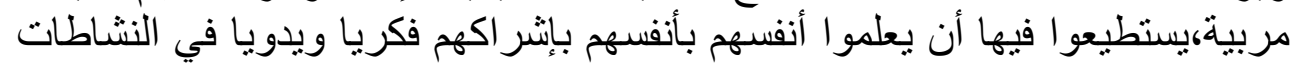


العلمية ،بالإضافة إلي إتاحة الفرصة أمام المتعلم لحل المشكلات العلمية، وحثهم نحو

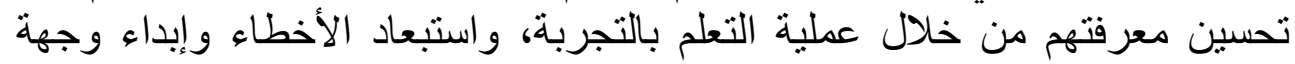
نظر هم بصدق وحرية.

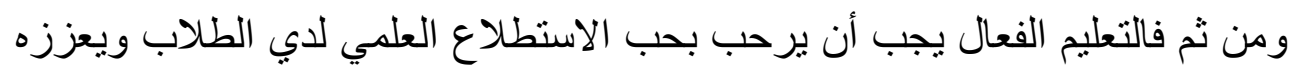

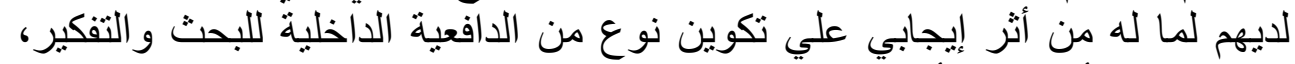
ومن هنا تنشأ النواة الأساسية لتكوين جيل جديد قادئ تادر علي مواجهة تحديات العصر ومو اكبة المستجدات.

كما يُعد حب الاستطلاع عاملا مؤثرَ في كثثر من جوانب التعلم وهو ما أوضحته

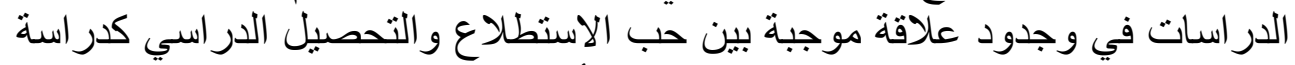

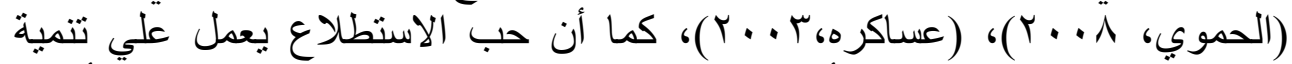

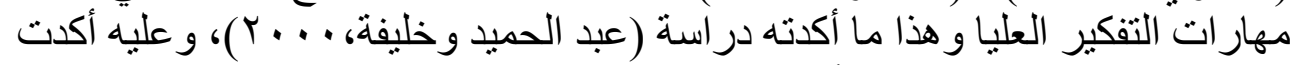

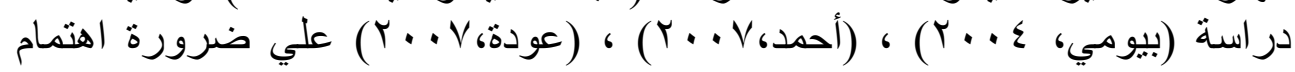

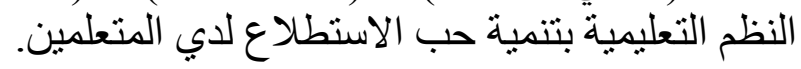

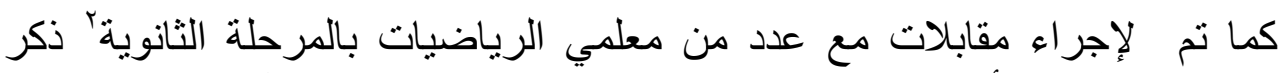

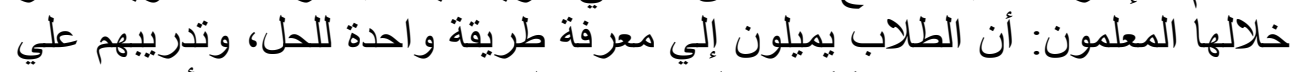

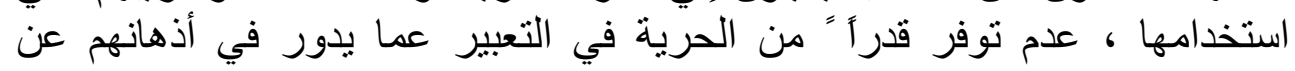

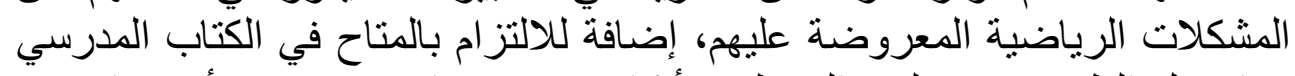

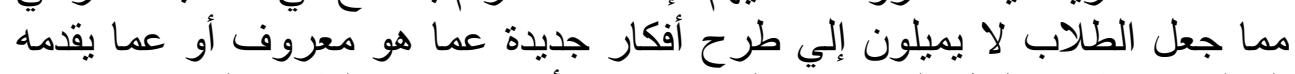

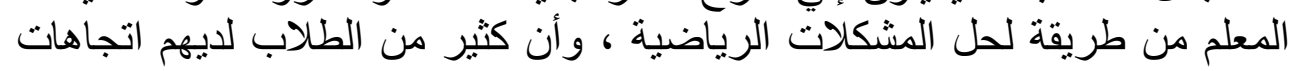
سلبية نحو الرياضيات.

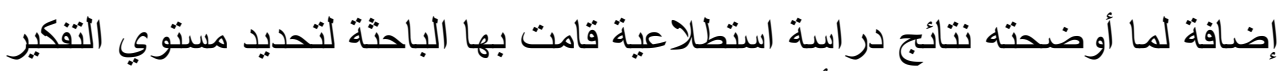

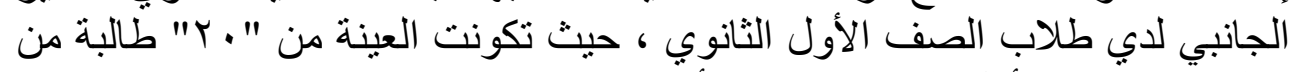

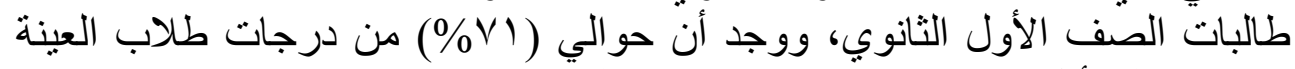

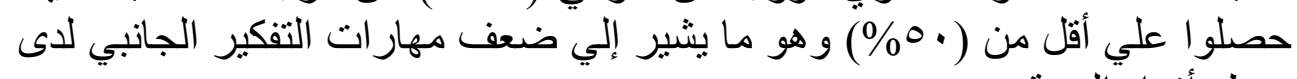
معظم أفر اد العينة.

وبذللك ينطلق البحث الحالي من اتجاهات عالمية ومحلية تؤكد ضرورة تضمين

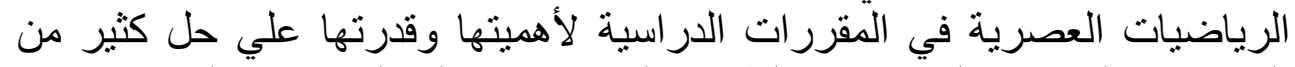

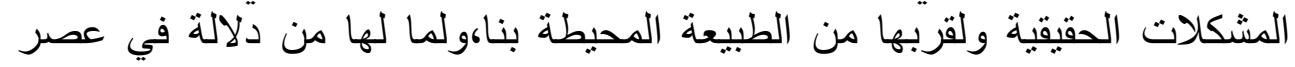

' عدد ـ 1 معلمين رياضيات بمرحلة التعليم الثانوى من طلاب اللابلوم المهنية والخاصة بكلية التربية. 
التكنولوجيا و المعلومات مما يمكنها من المساهمة في تنمية مهار ات التفكير الجانبي

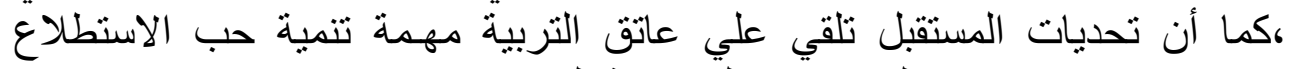
وتوسيع دائرة اهتمامهم بالمستجدات الرياضية المتجددة وتحبيبهم في در استها.

أسئلة البحث:

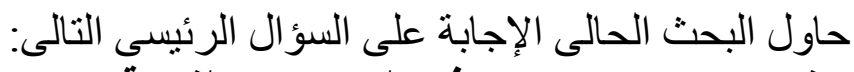

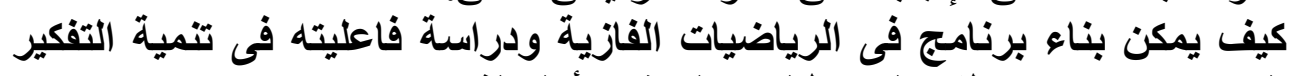

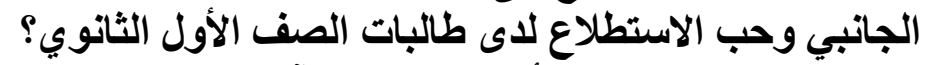

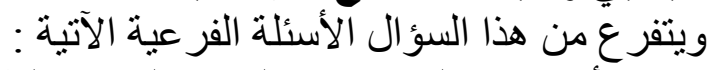

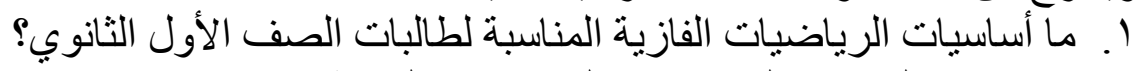

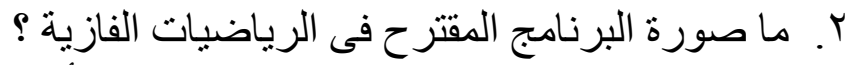

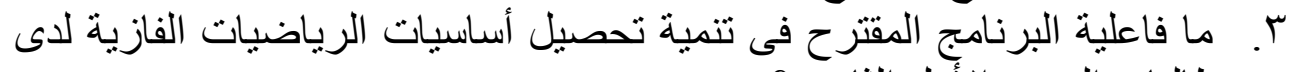

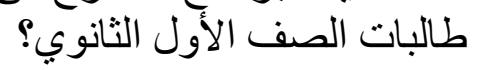
ع. ما فاعلية البرنامج المقترح فقى تنمية التفكير الجانبي لدى طالبات الصف الأول

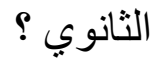
๑. ما فاعلُية البرنامج المقترح فى تتمية حب الاستطلاع لدى طالبات الصف الأول الثانوي حدود البحث: البوي: اقتصر البحث علي الحدود الآتيه:

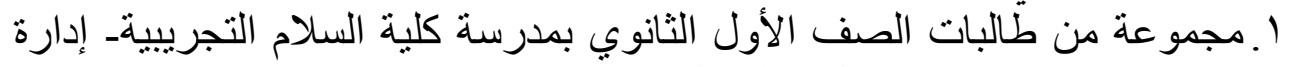

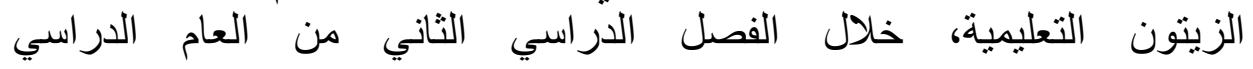

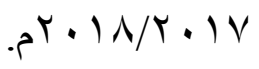
Y.بعض موضوعات الرياضيات الفازية: (المجموعات الفازية، الحساب الفازي، الهندسة الفازية، العلاقات الفازية). r. مهار ات التفكير الجانبي: (توليد إدراكات جدية).

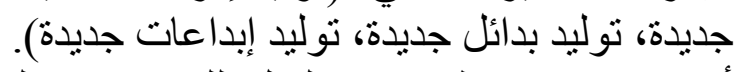

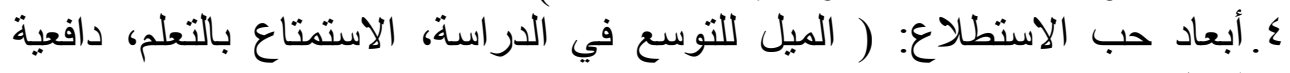

$$
\text { فروض البحث: أبحاز ). }
$$

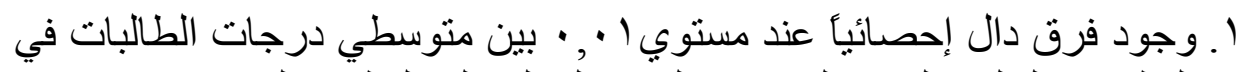

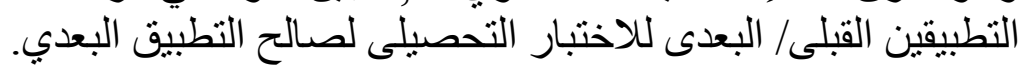




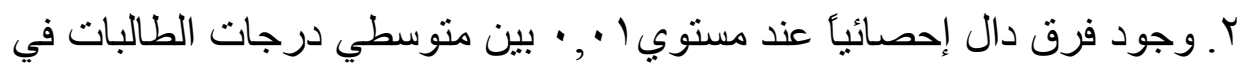

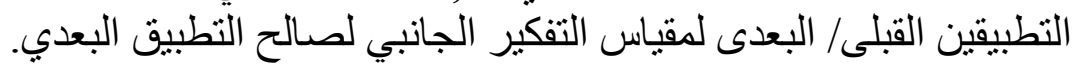

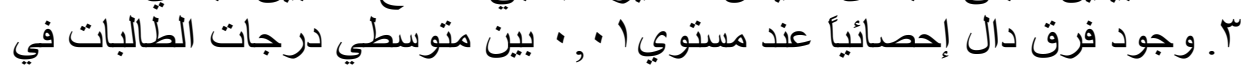

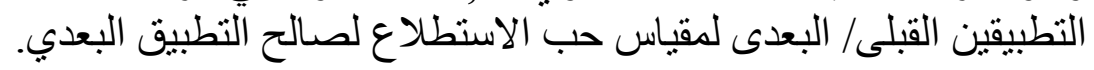

\section{مصطات البحث:}

- الرياضيات الفازية (FUZZY MATHEMATICS): أحد رياضيات اللايقين mathematics of uncertainty

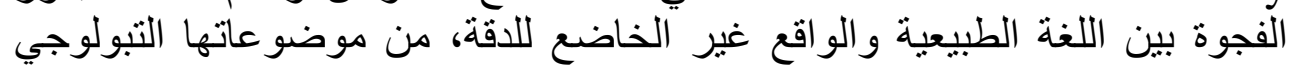

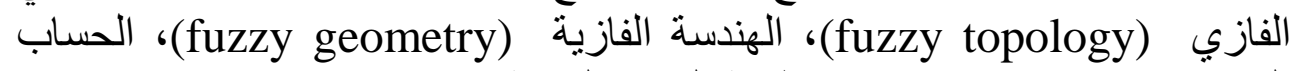
الفازيcfuzzy arithmetic) ، نظرية القياس الفازية (fuzzy measure theory) ، الفية (fuzy). - التفكير الجانبي: نشاط عقلي يتضمن قدرة الطالبة علي تقديم حلول غير فير نمطية

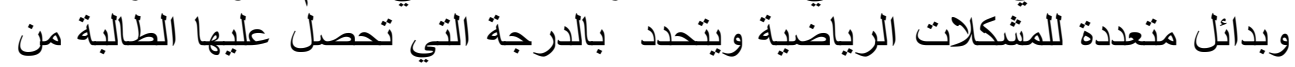

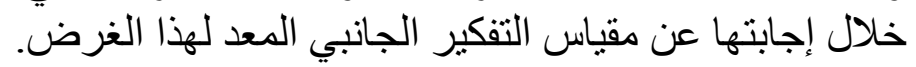

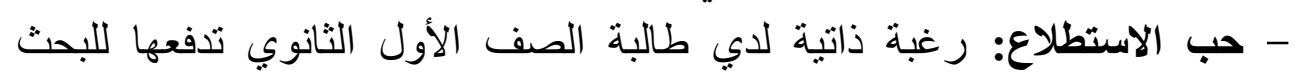

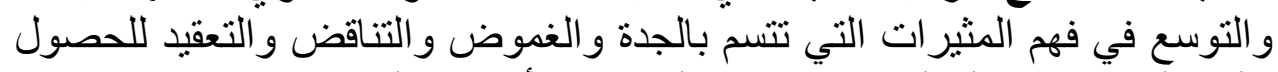

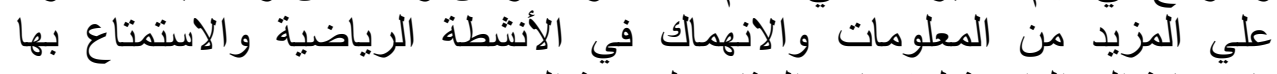

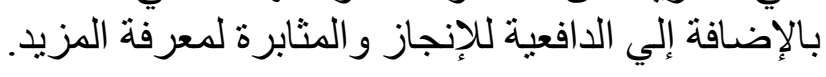

\section{خطوات البحث و إجراعاتهه:}

للإجابة عن أسئلة البحث و التحقق من فروضه سار البحث وفقا للخطوات التالية:

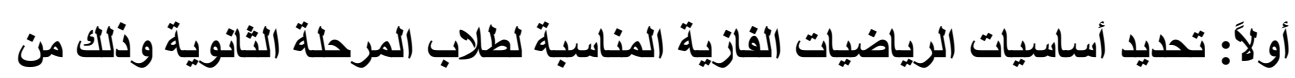
خلال: - nل

- در اسة نظرية عن الرياضيات الفازية.

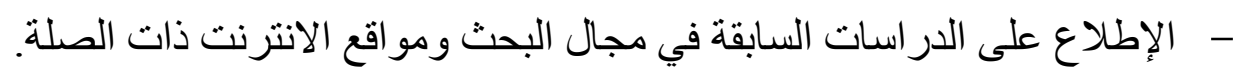
- در اسة خصائص طلاب المرحلة الثانوية.

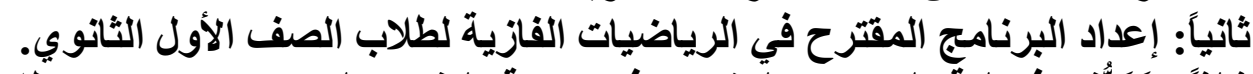

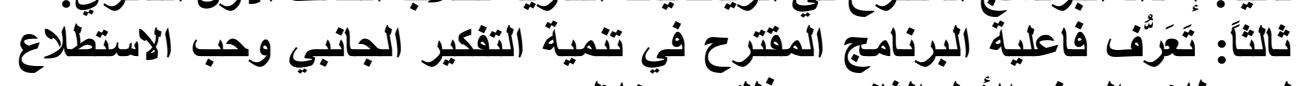

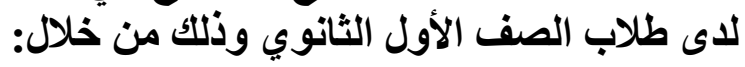

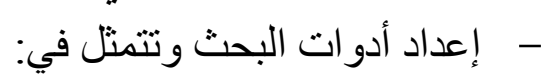




$$
\text { ب. . اختبار تحصيلي في الرياضيات الفازية. }
$$

- تطبيق أدوات البحث قبليا على مجمو عة البحث.

- - تدريس البرنامج المقترح ل لمجموعة البحث.

- تطبيق أدوات البحث بعدياً على مجموعة البحث.

- - رصد الدرجات ومعالجتها احصائياً وتفسير ها ومناقتنتها.

- - تقديم التوصيات و المقترحات في ضوء مات ما أسفرت عنه نتائج البحث.

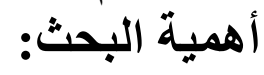

قد يفيد هذا البحث كلا من من:

ا. مخططي ومطوري المناهج : حيث يقدم برنامج في الرياضيات الفازية والتي

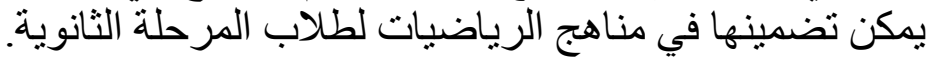

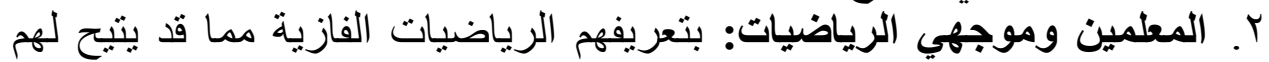

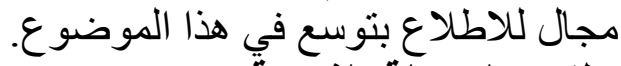

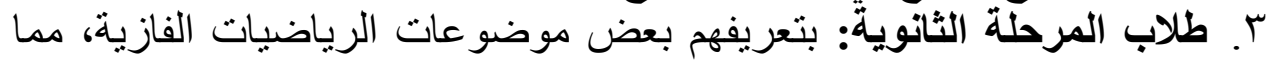

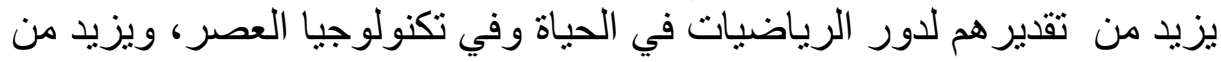

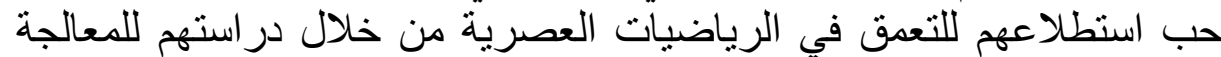

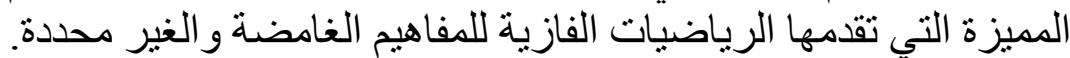

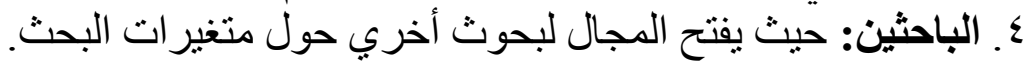

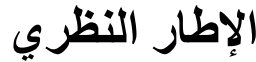

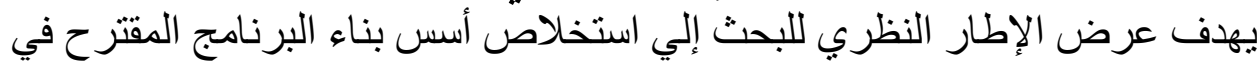

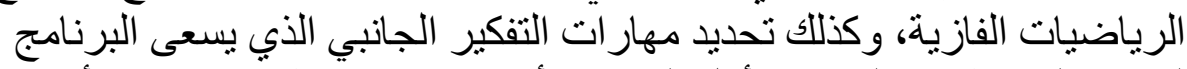

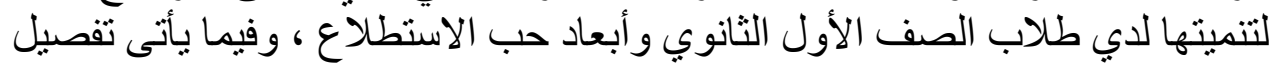

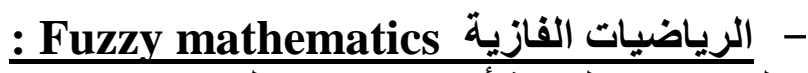
الرياضيات الفازية أحد رياضيات الفيات اللايقين mathematics of uncertainty التي

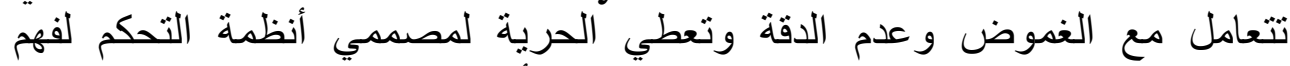

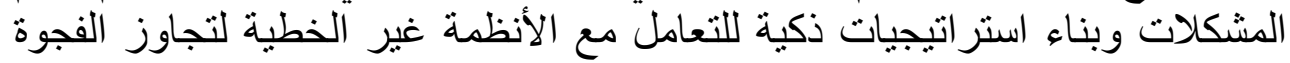

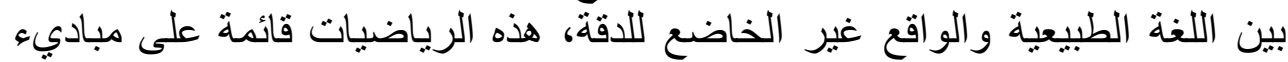
نظرية المجمو عات الفازية و المنطق الفازي، ولئ وفيما يلي توضيح لكل منهما: 


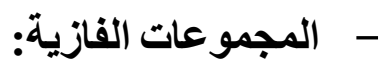

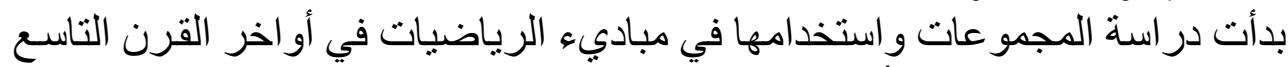

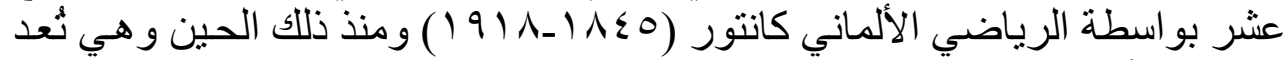

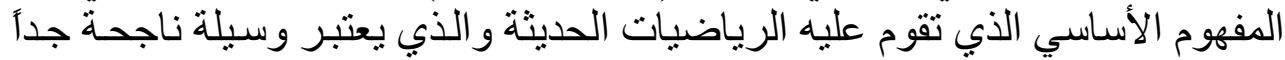
لتوحيد لغة الرياضيات و اعتبار ها وحدة منماسكة.

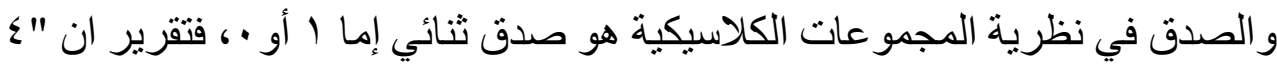

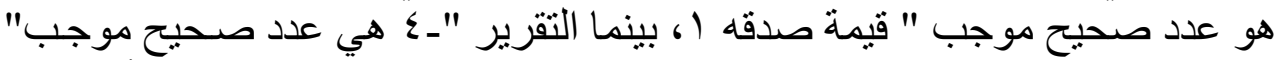

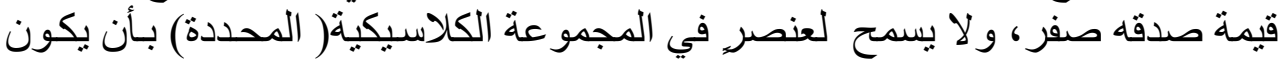

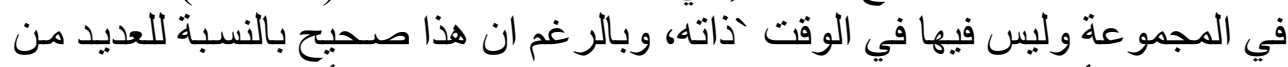

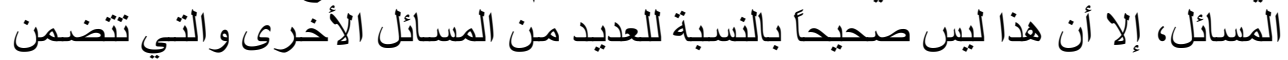

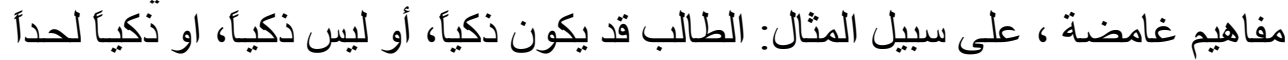

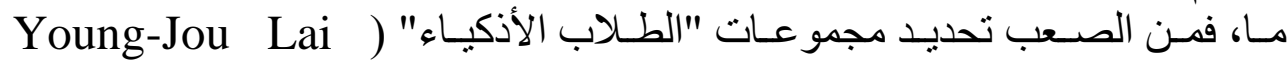
.\&Ching , 1992,14

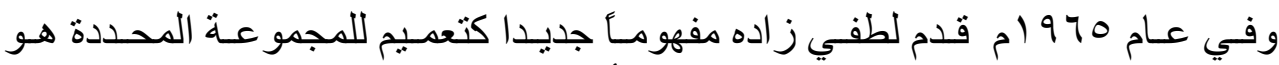

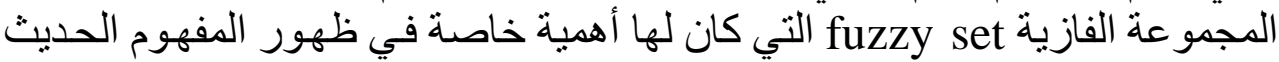

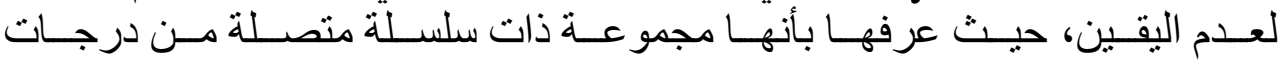

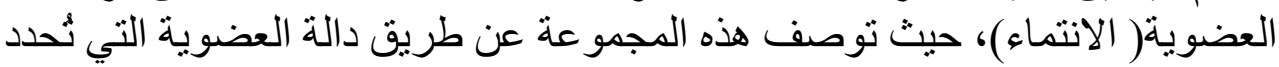

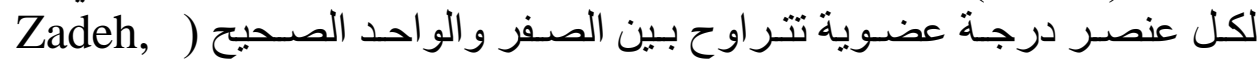
$(1965,29$

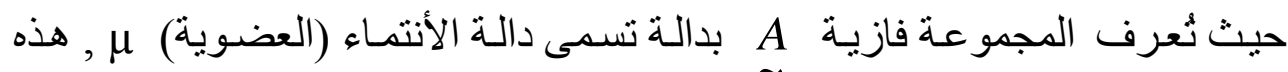
الدالة تربط كل عنصرx في المجموعة A

$(1 \mu \leq$

حيث ان قيمة الدالة بر لعنصر x يمثل درجة انتماء (عضوية ) العنصر x في ه

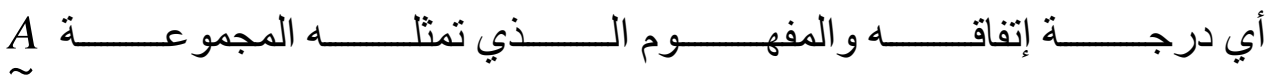

$$
\mu_{-}(x): X \rightarrow[0,1]
$$

ويمكن التعبير عن المجموعة الفازية كالتالي: 
وللمجمو عات الفازية القدرة على التعبير عن التحو لات التدريجية من الإنتماء إلى عدم التحاء

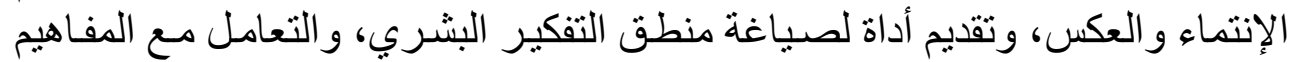

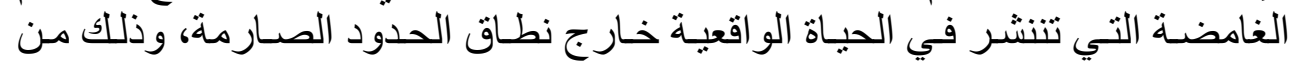

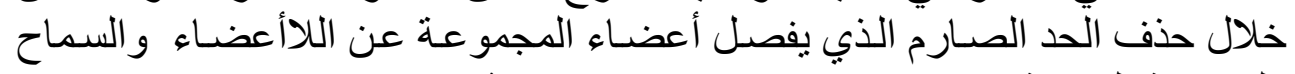

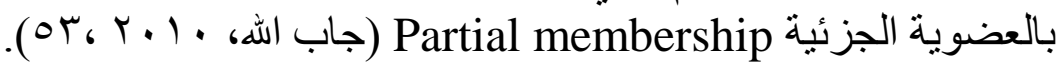
ورن الفروق بين المجموعة المحدة والمجموعة الفازية: أن المجموعة الفازية

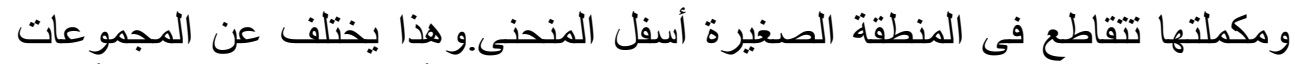
العادية ( المحددة) التى فيها

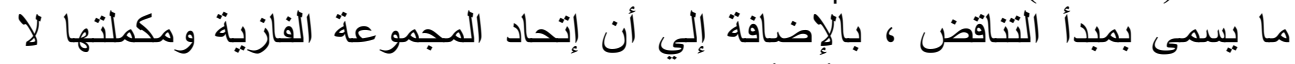
تساوى المجمو عة الشاملة X) أى أن A A A A العادية التى فيها AU A $=$ A وهذا ليناظر أن التقرير أو نفيه يكون صحيح - وهو يمكن الوصول إليه من النفى مرتين لقانون ديمورجان - و المعروف بمان فيدأ إستبعاد

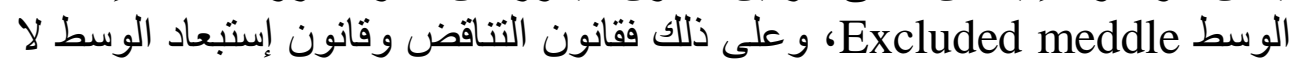

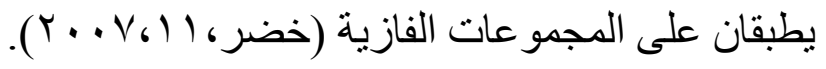

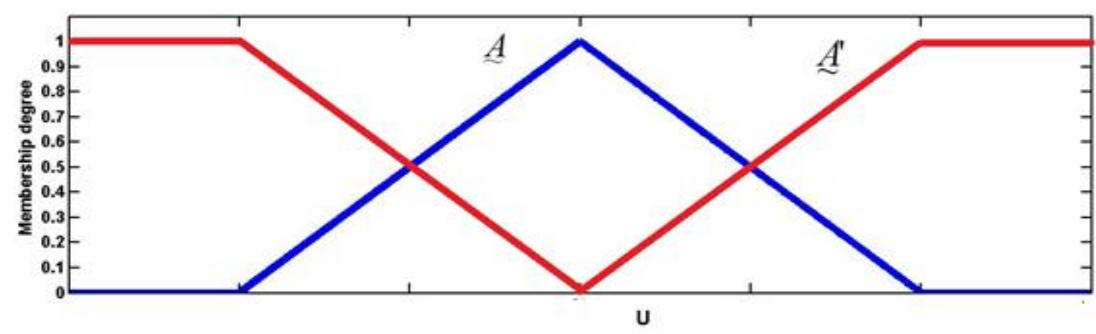

ثثَّة اختلاف أخر بين المجموعات الفازية و المجموعات المحددة هو أن دالة الانتماء

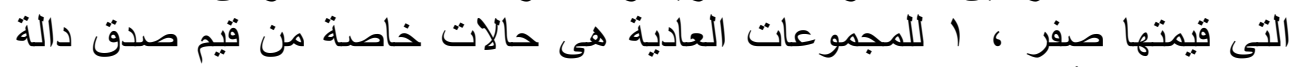

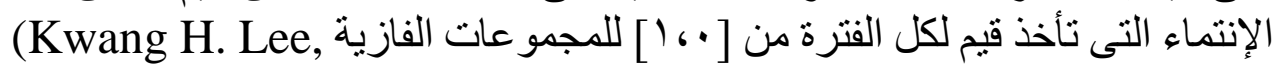
2005, 208)

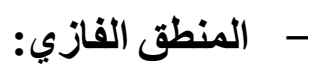

بعد تطوير زاده نظرية المجموعات الكلاسيكية( المحددة) قدم المنطق بمعناه

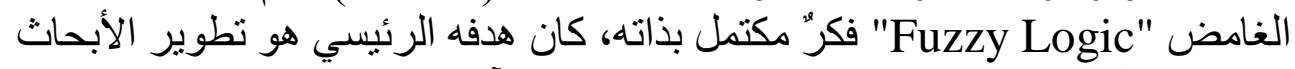

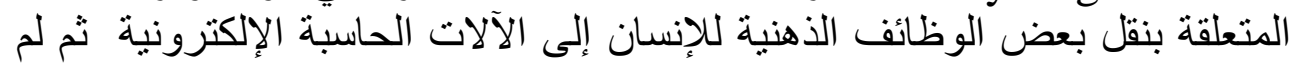


تلبث أن أصبحت عصب الأجهزة الإلكترونية الحديثة بأشكالها المختلفة .(Garrido,2012)

عرّف Zadaeh (1988) المنطق الفازي بأنه المنطق الذي يهتم بالمباديء

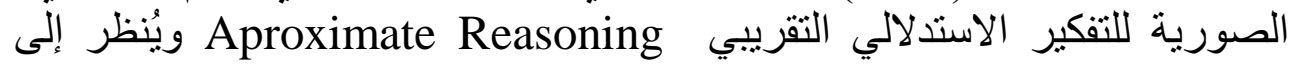
التفكير الاستدلالي الدقيق بإعتباره حالة حدية "Limiting case".

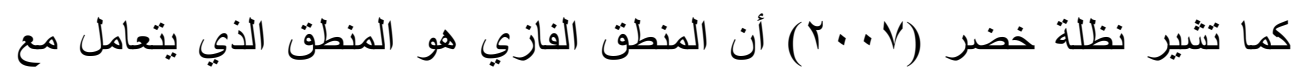

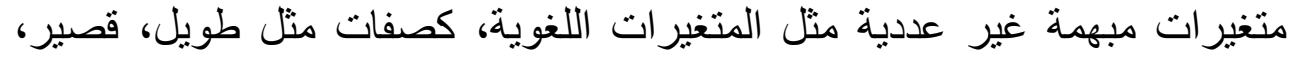

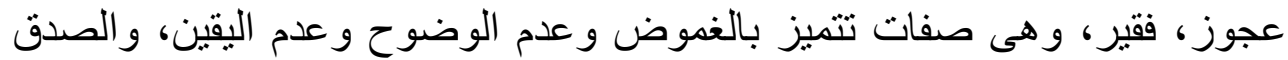

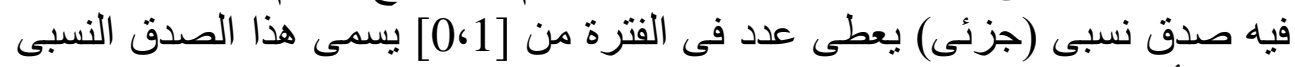

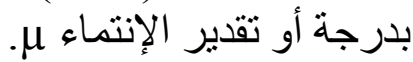

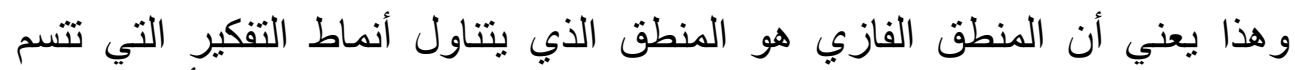

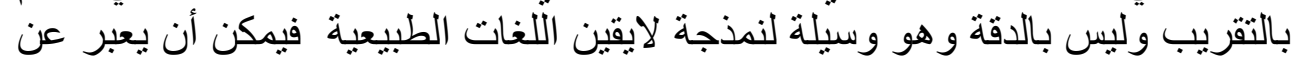

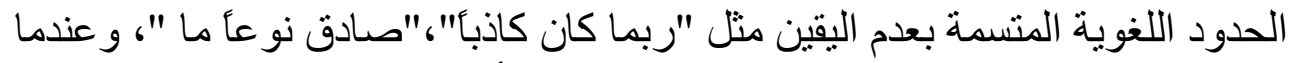
يطبق المنطق الفازي على الحاسبات فإنه يسمح لها لأنس الن تحاكي عملية التفكير الإنساني

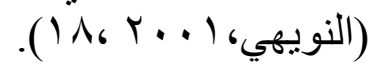

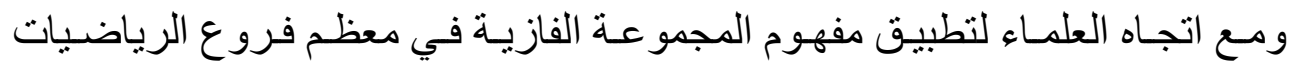

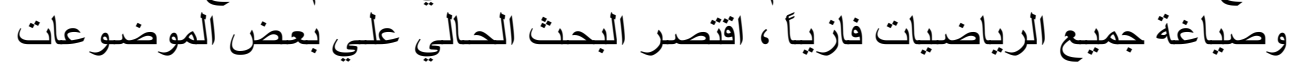

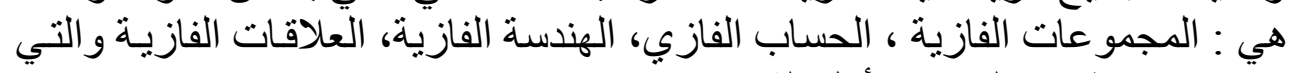

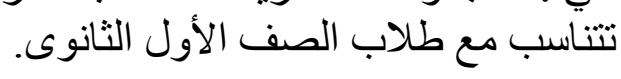

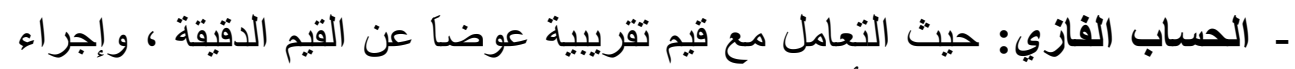

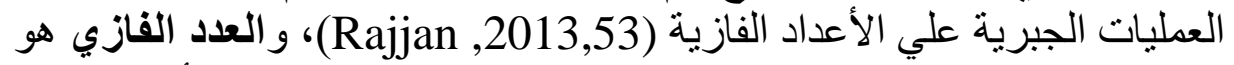

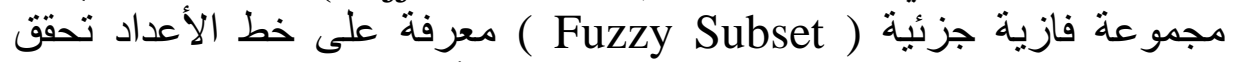

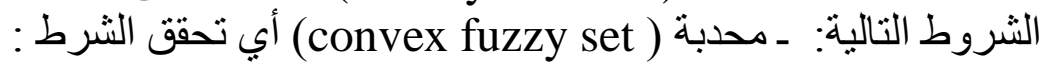

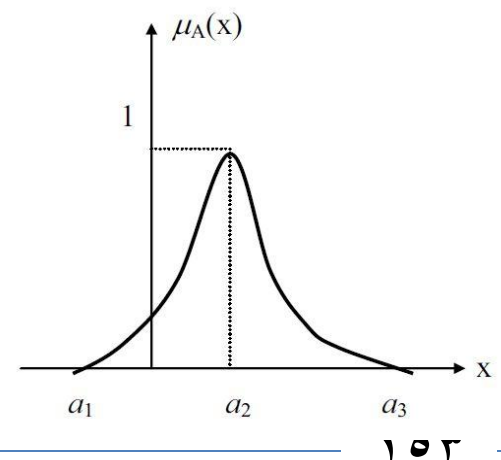




\section{IFx, $y, z \in \underset{\sim}{\text { Aand }} \quad x<y<z \quad$ then $\underset{\sim}{\mu_{A}}(y) \geq \min \left[\underset{\sim}{\mu_{A}}(x), \underset{\sim}{\mu_{A}}(z)\right]-$}

ـ تكون مجمو عة فازية معيارية ( normalized fuzzy set) اي تحقق الثرط:

$$
\exists x \in R \quad \mu_{\sim}(x)=1
$$

-

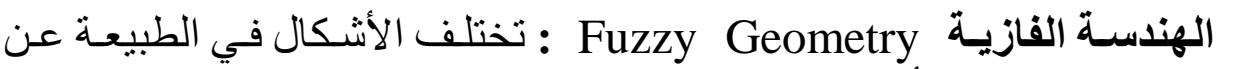

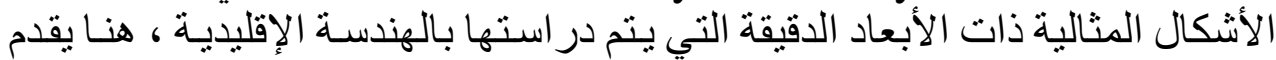

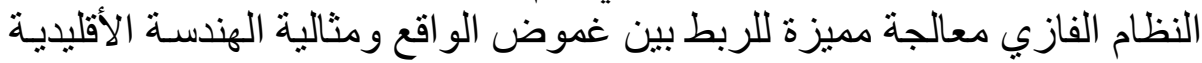

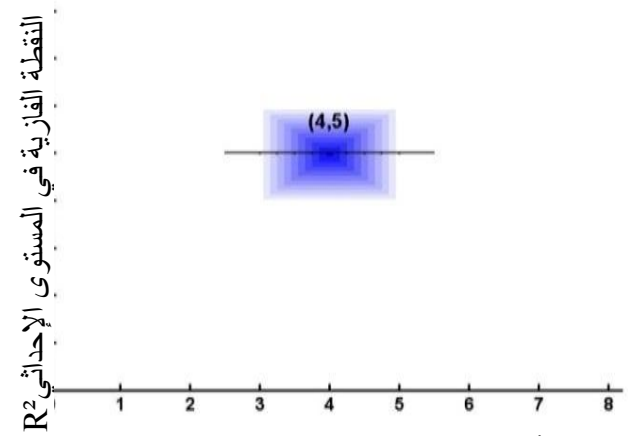

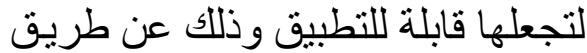

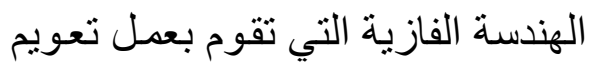
fuzzification الاقليدية. ففي مقابل النقطة و القطعة المستقيمة

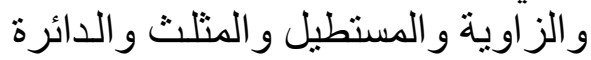

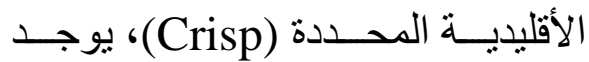

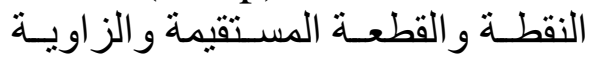

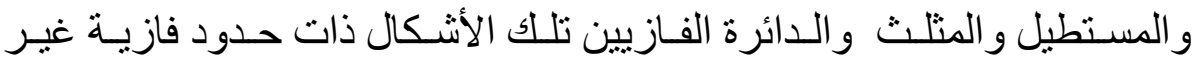

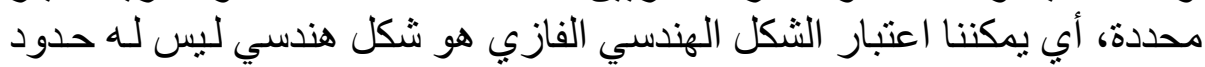

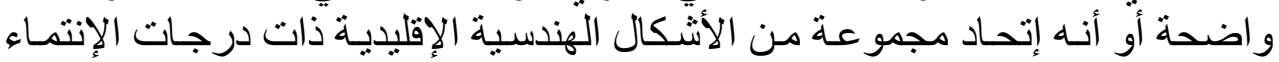
المختلفة (Imran \& Sofyan, 2012,270)

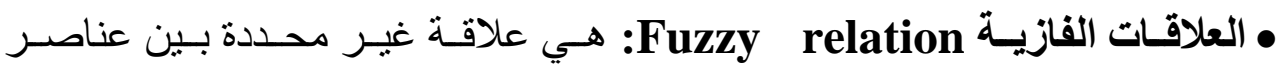

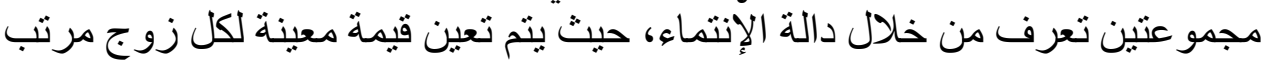

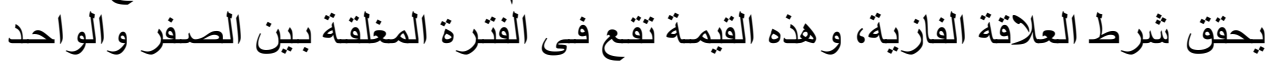

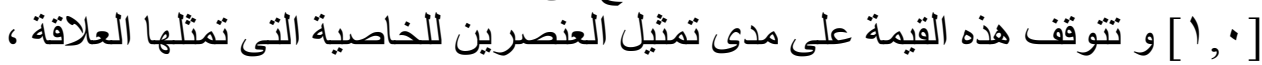
وتعرف رياضيا كالتالى:

$$
R=\left\{\left((\mathrm{x}, \mathrm{y}), \mu_{\mathrm{R}}(x, y)\right): \mu_{\mathrm{R}}(x, y) \geq 0, \mathrm{x} \in \mathrm{A}, \mathrm{y} \in \mathrm{B}\right\}, \mu_{\mathrm{R}}: A \times B \rightarrow[0,1]
$$


فالعلاقة x = المعرفة على الأعداد الحقيقية الموجبـة تتحوّل إلى علاقة فازيـة إذا
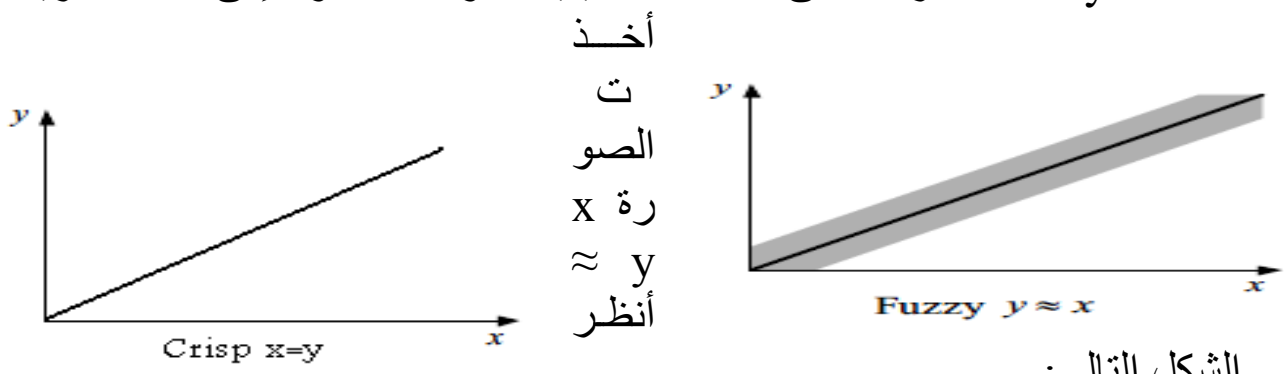

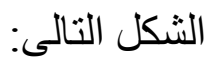

تطبيقات الرياضيات الفازية: تتعدد تطبيقات الأنظمة الفازية في مجالات عدة منها:

- - أنظمة التحكم الفازية :

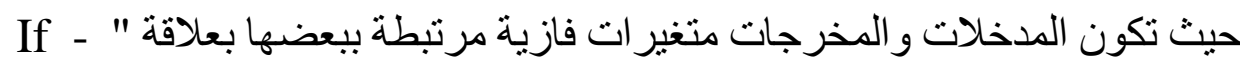
"then

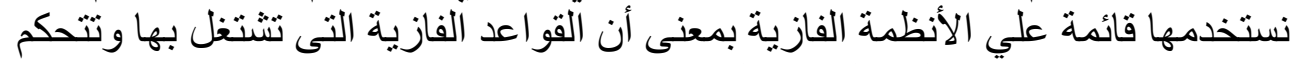

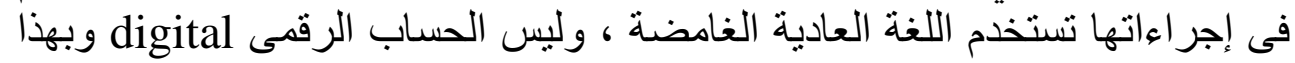
فهي تحاكي تفكير الإنسان فى تعامله مع الو اقع .

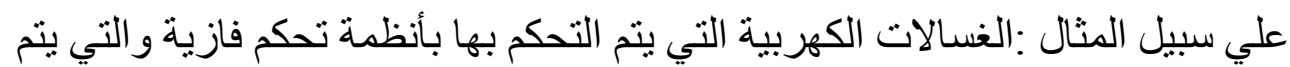

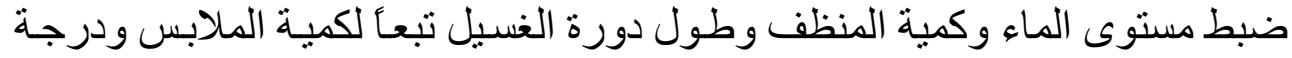

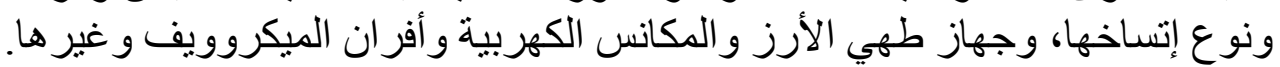
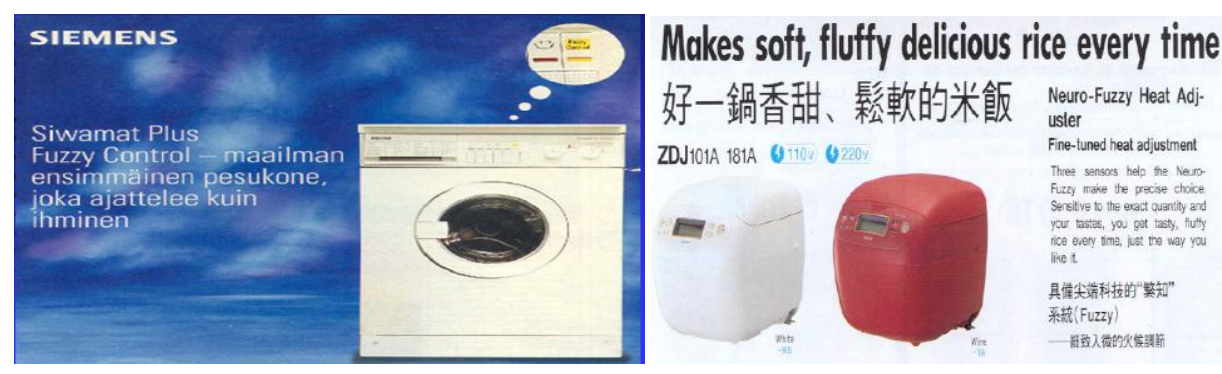
-

هي نظم قادرة على حل مشكلات وتقديم استشارات في مجال معين بنفس الطريقة و المستوى الذي يقوم به الخبير البشري في هذا المجال.

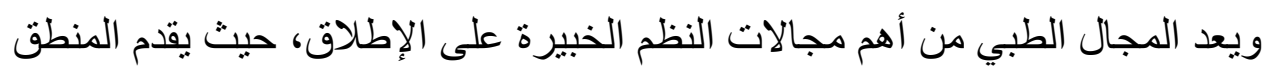

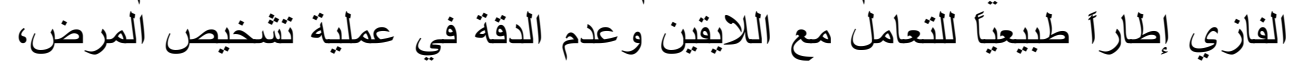

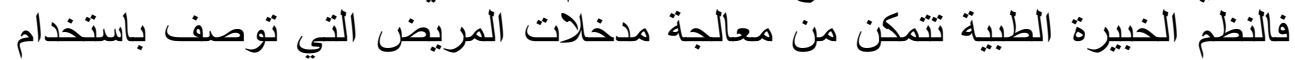
حدود لغوية غامضة وتطبيق عملية اتخاذ قرارات الأطباء اللغوية المعقدة (جاب الله

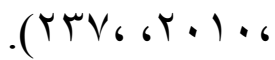

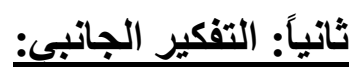

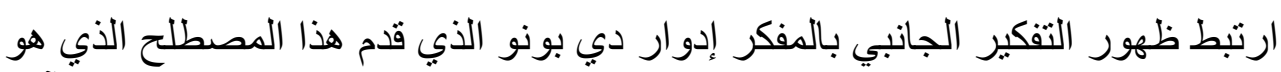

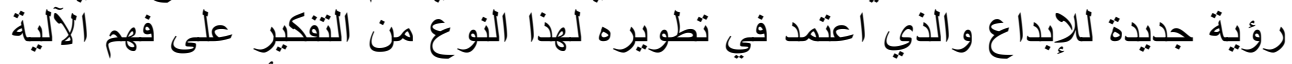

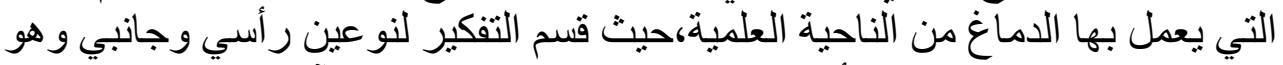

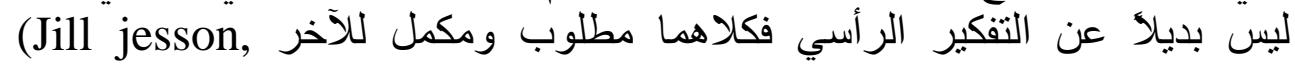
.2012,76)

وقد أوضح De Bono (1990)أن التفكير الرأسي يعتمد علي المسار المألوف

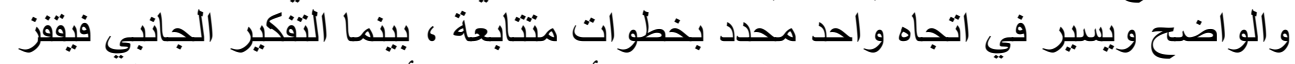
من خطوة لإخري دون الاعتماد علي مسار مألوف يبتكر أكبر قدر من البدائل وييقى

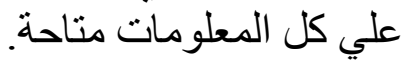

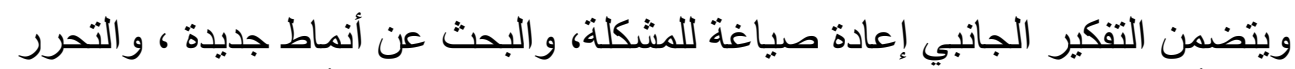

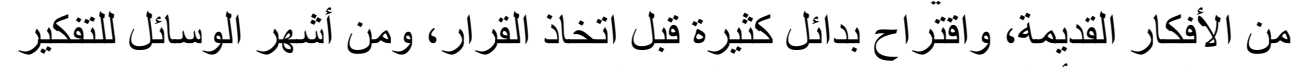

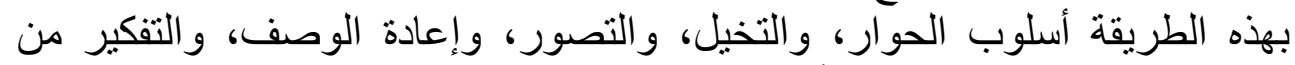

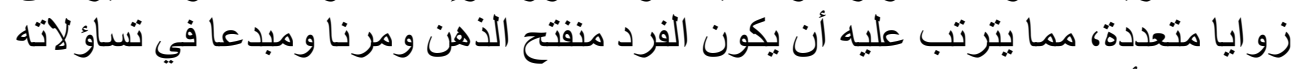

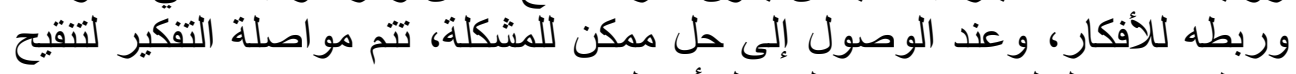

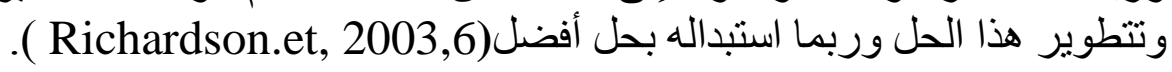

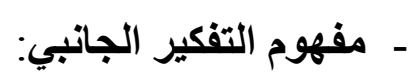

عرفه De bono (1998) بأنه طريقة مبدعة تخيلية لحل الششاكل تؤدي إلي تغيير تصور ات الفرد ومفاهيمه عن مشكلة ما ، ويعرفه jill lesson (2012) بأنه البحث نئن 


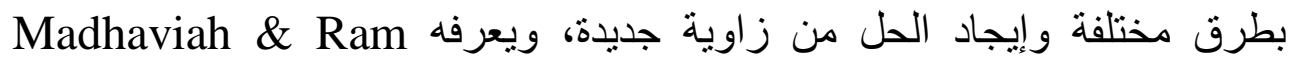

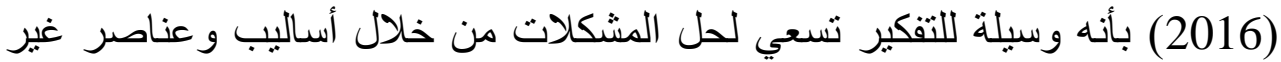

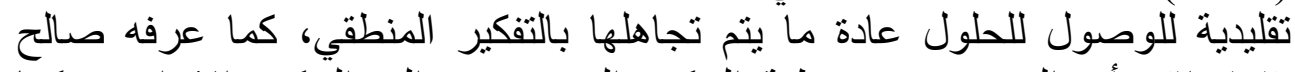

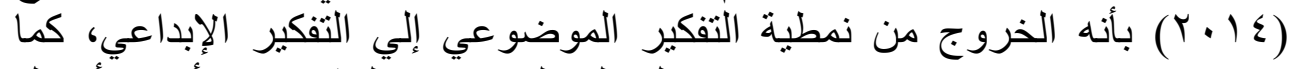

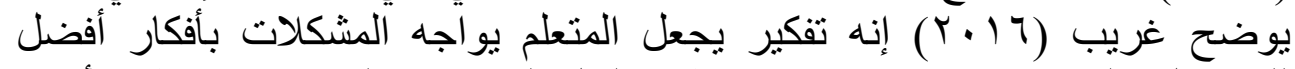

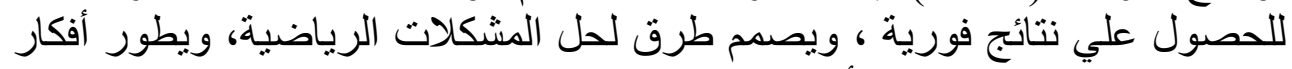
جديدة، ويسعي إلي تغيير الأفكار و المدركات ، لتوليد مفاهيم ومدركات جديدة قابلة الريلة

للتطبيق.

ومما سبق يتضح إن التفكير الجاتبي يتسم بعدة خصائص أهمها إنه يساعد علي: - م النظر إلي أكثر من جهة منكل لحل المشكلات.

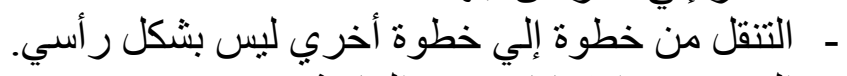

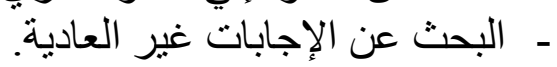
- م- - زيادة عدد الأفكار الجديدة القابلة للتطبيق.

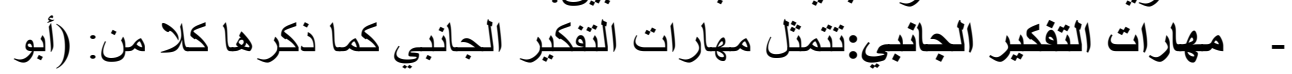

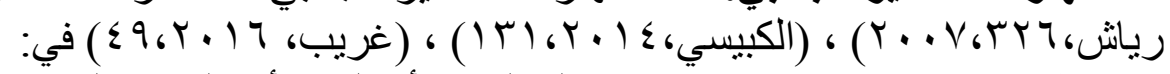

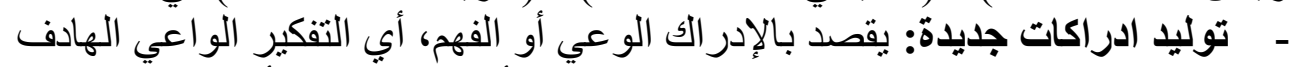

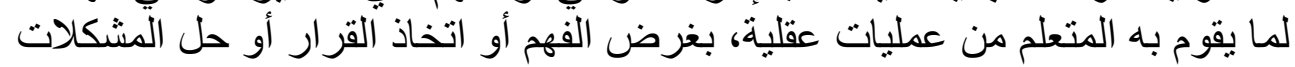

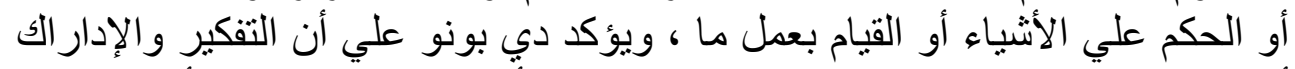

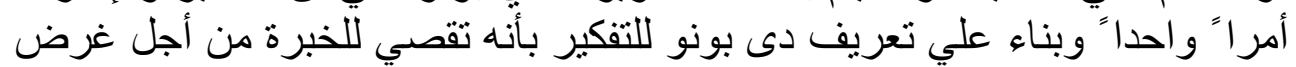

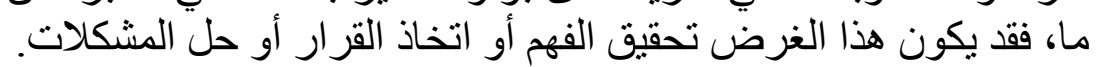

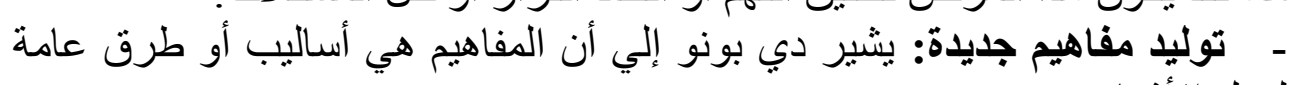

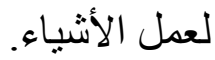
- توليد أفكار جديدة: يُعرف دي بونو الفكرة بأنها شي يتصور من خلال العقل،

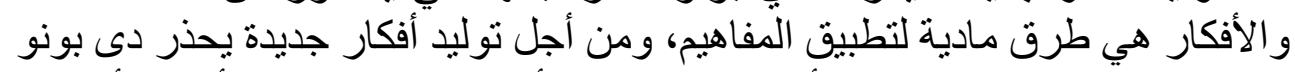

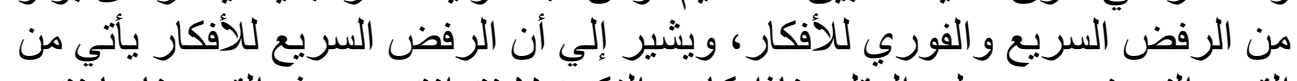

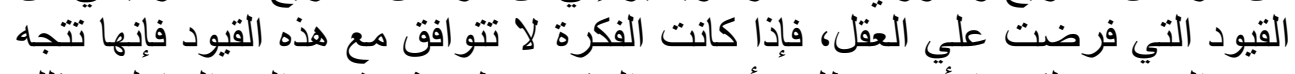

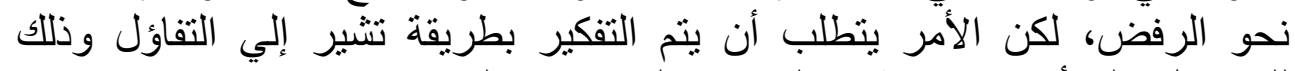
للحصول علي أفكار إبداعية ، و التركيز علي تحسين الفكرة. 
- توليد بلائل جديدة: يهنم التفكير الجانبي باكتشاف أو توليد طرق أخري لإعادة

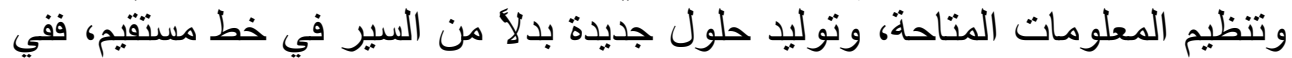

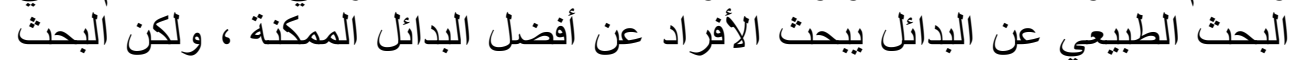

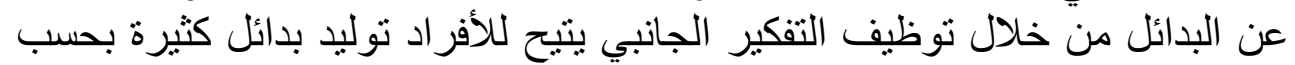

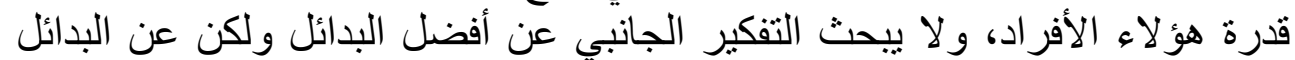

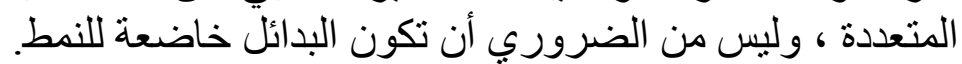

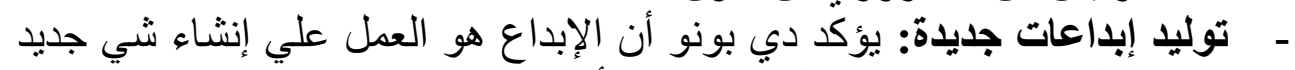

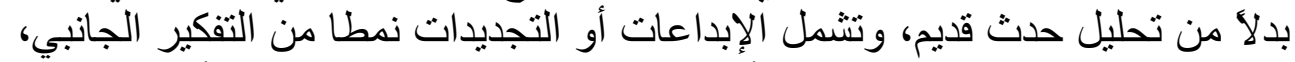

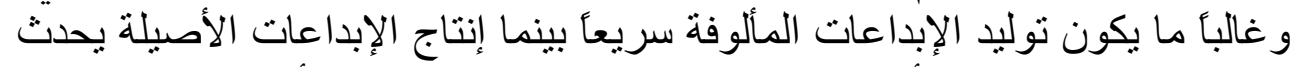

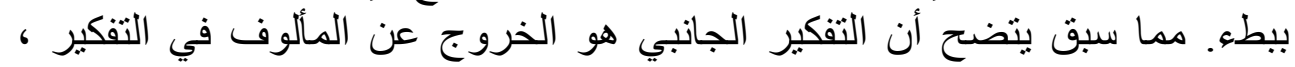

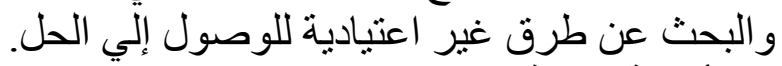

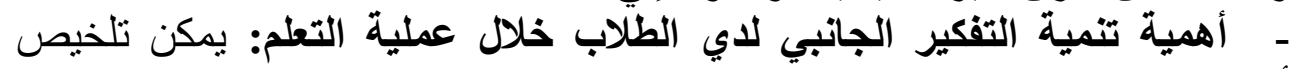

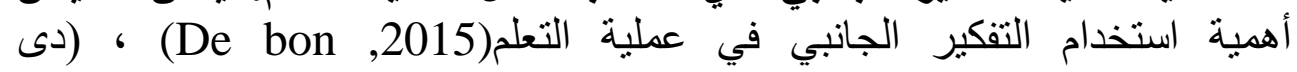

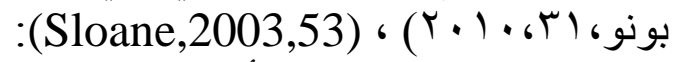
- - تقدير قيمة التنوع في الأفكار بين المتعلمين.

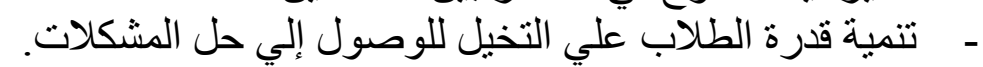

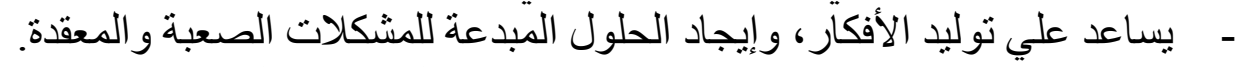

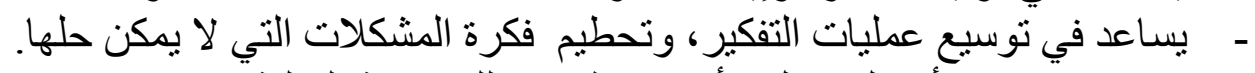

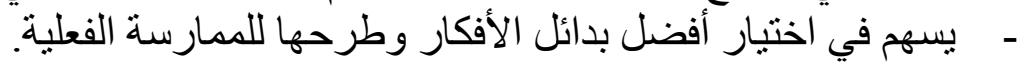

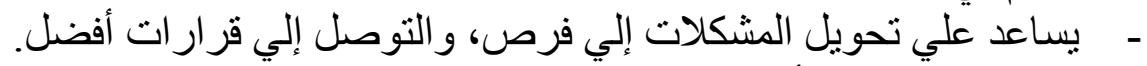
- - - - يشيع مناخ إيجابي أثناء التعلم.

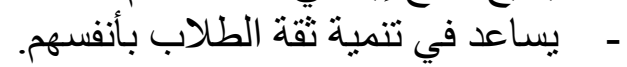

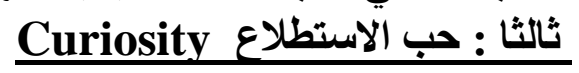

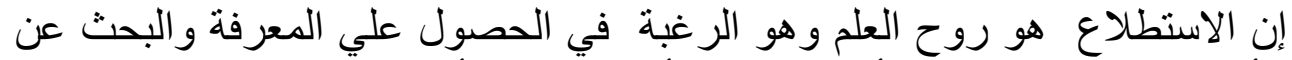

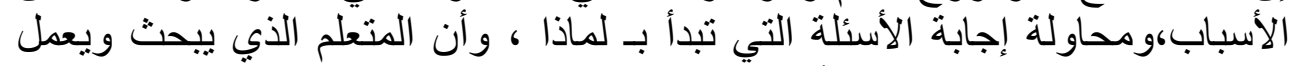

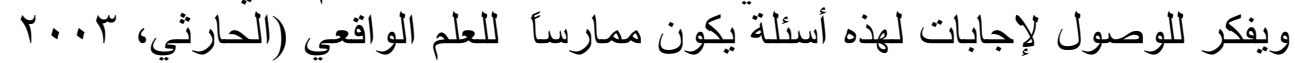

كما تظهر أهمية تنمية حب الاستطلاع لدي المتعلم كمقوم من المقومات اللازمة

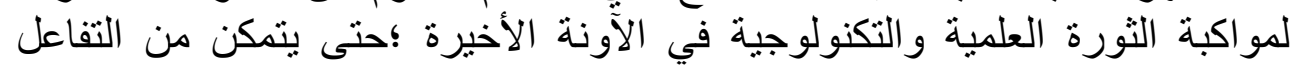

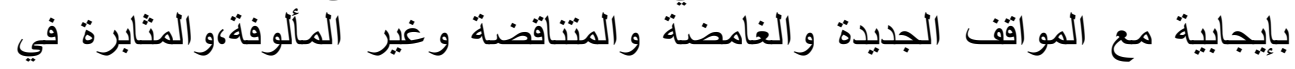


الفحص الدقيق لكل ما يحيط به لانتقاء ما هو نافع له و لاكتساب خبرات جديدة

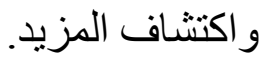

\section{- مفهوم حب الاستطلاع Definition Of Curiosity:}

عرف Deb rosenfeld (2007) حب الاستطلاع بأنه رغبة في المعرفة تؤدي إلي

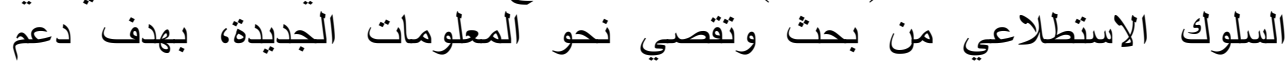

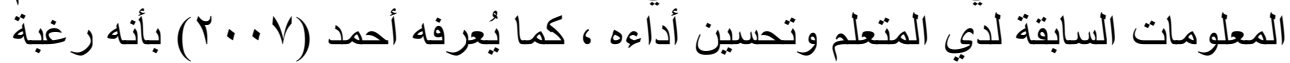

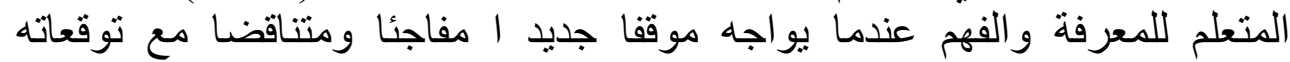

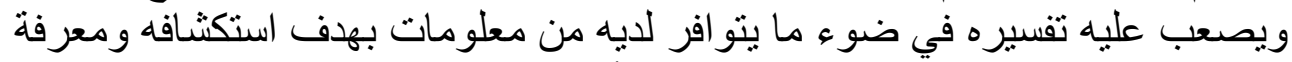

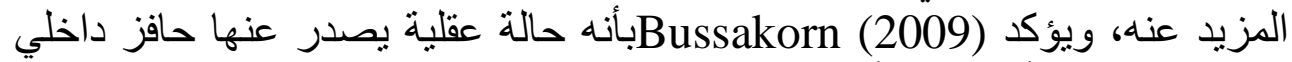
يدفع الفرد إلي أن يتعلّم أكثر عن شيء ما فيقوم بترتيب الاستفسارات والبحثة

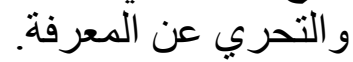

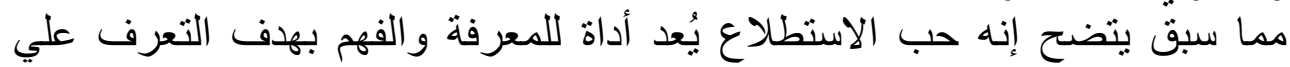

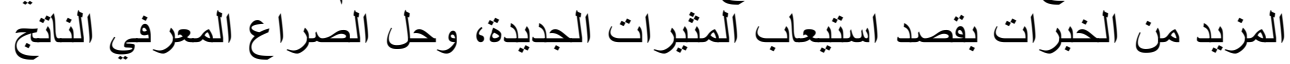

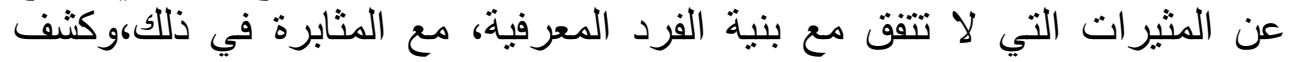

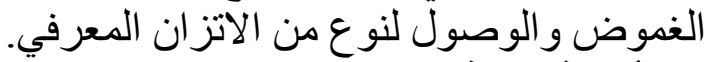

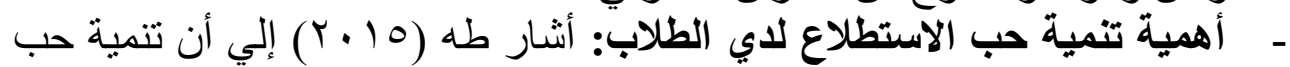

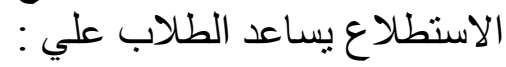
- تنشيط الدافعية نحو التعلم. ـ ت تنمية المرونة و التفتح العقلي.

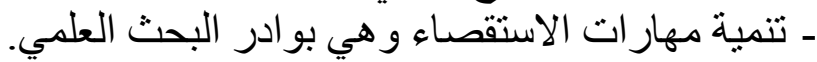

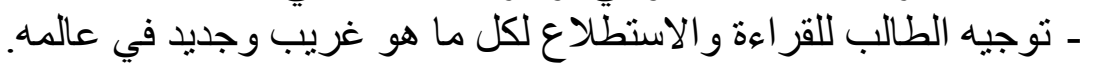

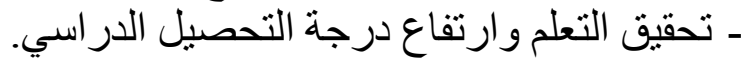

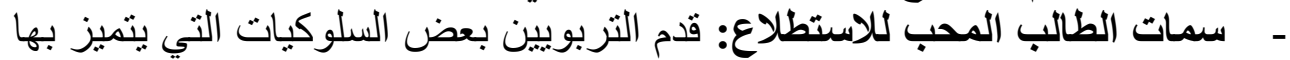

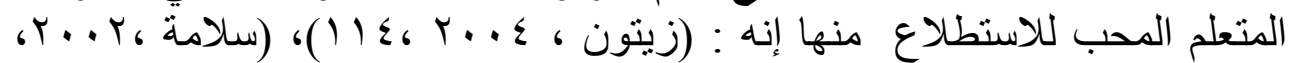

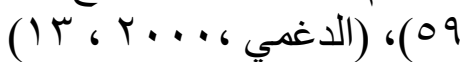
- ينتبه إلي المواقف الجديدة،ويبدي الرغبة في الاستفسار عن جوانب هذا الموقف

- يسأل الكثير من الأسئلة،يستفسر عن الأشياء التي تثير انتباهـه.

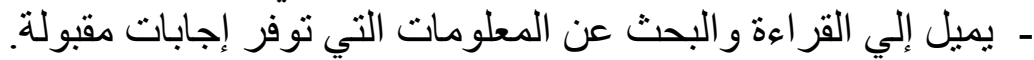

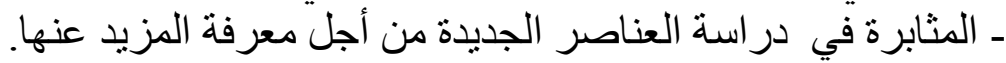

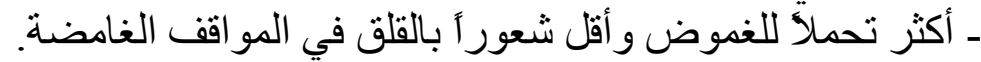
إجراعاث البحث: أنم: 
يتناول هذا الجزء من البحث الإجراءات التي اتبعتها الباحثة لإعداد أدوات البحث

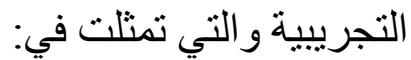
أولا: تحديد أسباسيات الرياضيات التيات الفازية المناسبة لطلاب المرحلة الثانوية: من

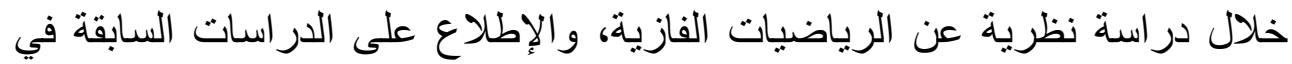

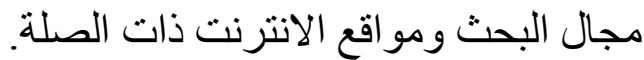

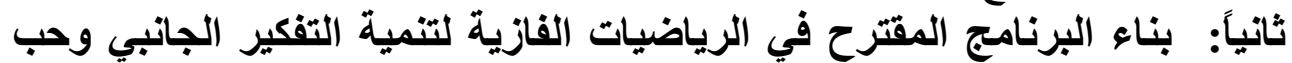

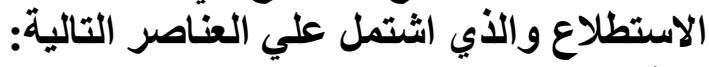

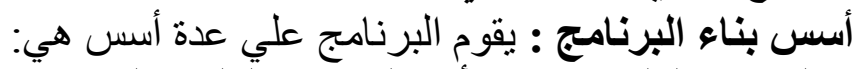

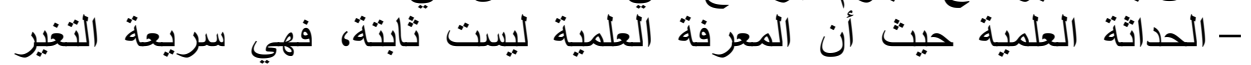

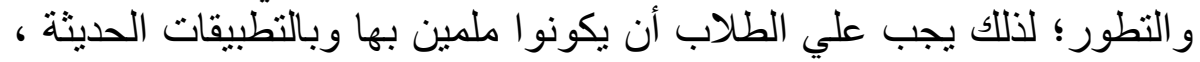

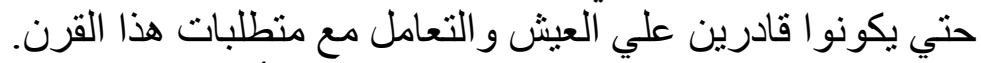

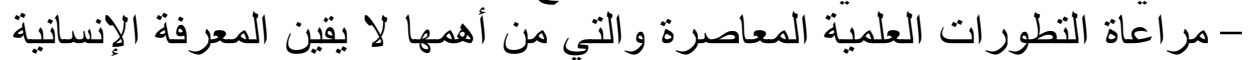

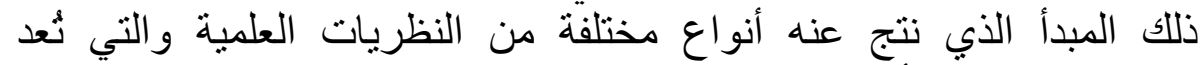
الرياضيات الفازية أحدهما، ومر اعاة التحام المعرفة أنة وتطبيقاتها.

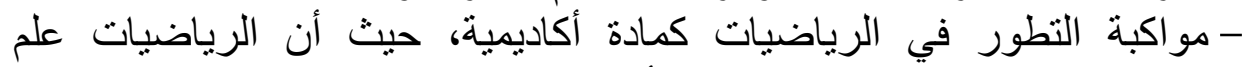

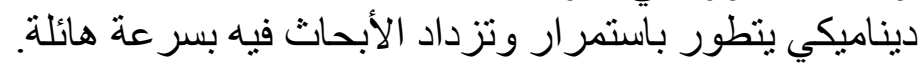

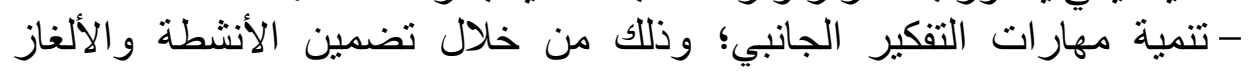

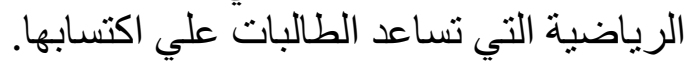
- تنمية حب الاستطلاع كمقوم من المقومات اللازمة لمواكية اكبة الثوابة الثورة العلمية

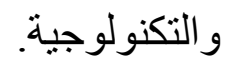
- استخدام تقنيات تكنولوجيا المعلومات والحاسبات وشبكاتها خلال تدريس

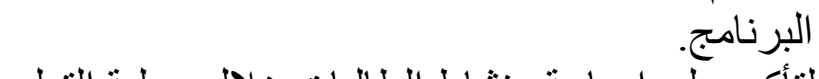
- التأكبد على إيجابية ونشاط الطالبات خلال عملية التعلم.

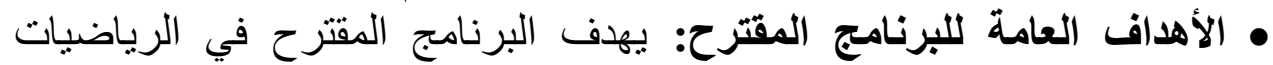

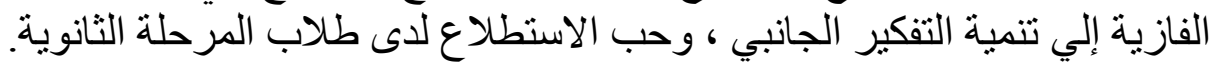
محتوي البرنامج : يتكون البرنامج من أربع وحدات في الرياضيات الإنيات الفازية

جدول 1 :الخطة الزمنية لتدريس موضوعات البرنامج

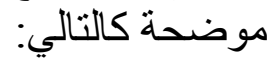

\begin{tabular}{|c|c|c|}
\hline عدد الحصص & الأرس & الموضوعات \\
\hline 1 & مر مرجعة علي المجمو عات & \multirow{4}{*}{$\begin{array}{c}\text { المجموعات الفازية (fuzzy set theory) } \\
\text { (الفية }\end{array}$} \\
\hline r & المجموعة الفازية. & \\
\hline r & مفاهيم أساسية على المجموعات الفازية. & \\
\hline$r$ & العمليات على المجموعات الفازية. & \\
\hline
\end{tabular}




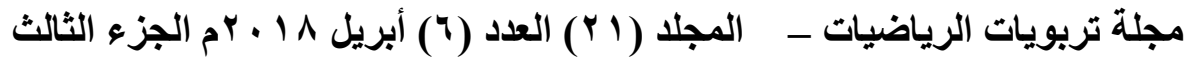

\begin{tabular}{|c|c|c|}
\hline$r$ & الأعداد الفازية. & \multirow{2}{*}{$\begin{array}{c}\text { (الحساب الفازي } \\
\text { (fuzzy arthimatic ) }\end{array}$} \\
\hline$r$ & العمليات على الاعداد الفازية. & \\
\hline r & الأشكال الهندسية الفازية. & \multirow{2}{*}{$\begin{array}{c}\text { الهندسة الفازية (fuzzy geometry) } \\
\text { (fuzy }\end{array}$} \\
\hline$r$ & محيط ومساحة الأثكال الهندسية الفازية. & \\
\hline r & العلاقات الفازية. & \multirow{2}{*}{$\begin{array}{c}\text { العلاقات الفازية } \\
\text { (fuzzy relation) }\end{array}$} \\
\hline 1 & العمليات علي العلاقات الفازية. & \\
\hline 11 & & المجموع \\
\hline
\end{tabular}

• استراتيجيات وطرق التدريس المستخدمة في البرنامج : استخدمت الباحثة

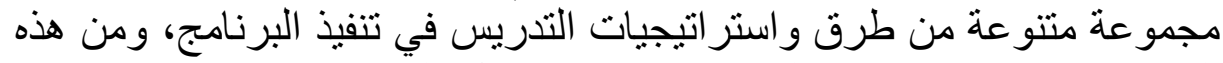

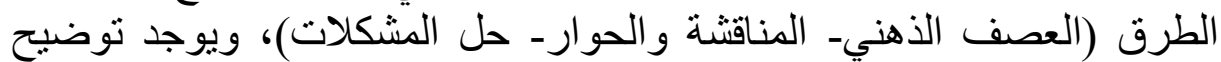
لخطو ات كل الطرق و الآستر اتيجيات في مقدمة دليل المعلم بالبرنامج. لون.

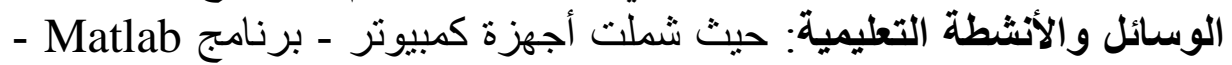

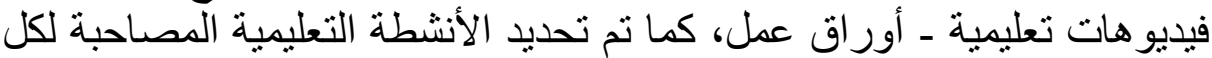

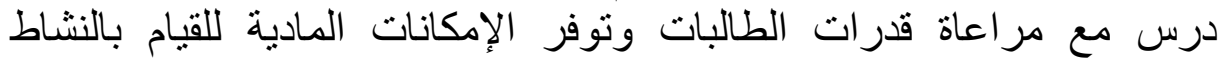

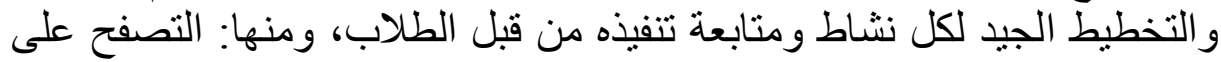

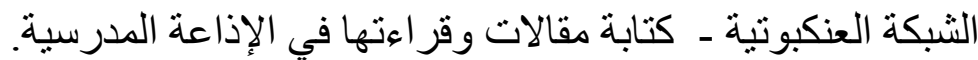

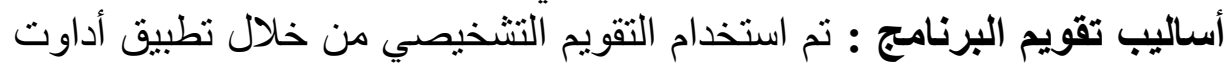

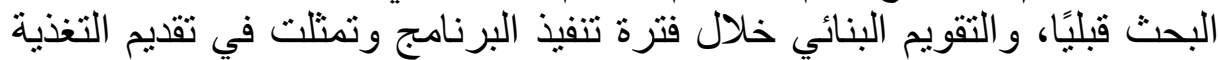

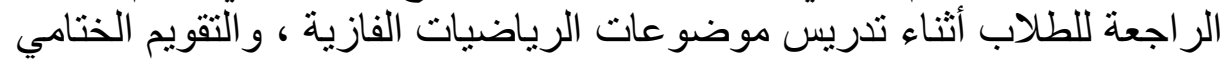

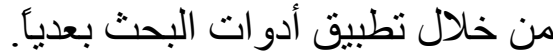

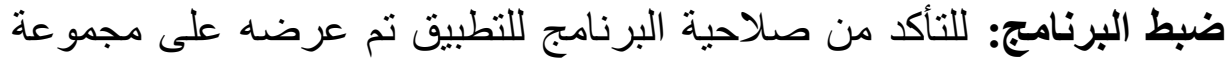

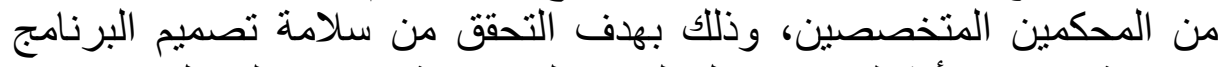

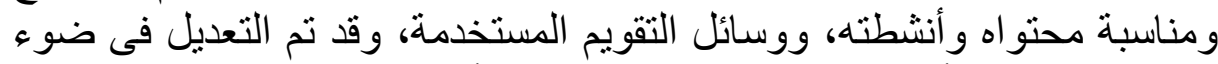

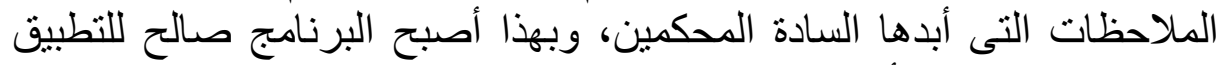
على طلاب الصف الأول الثانوي.

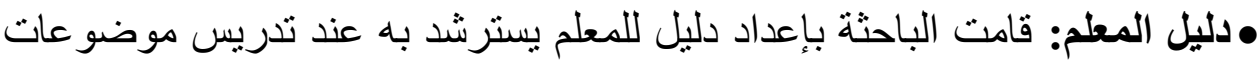

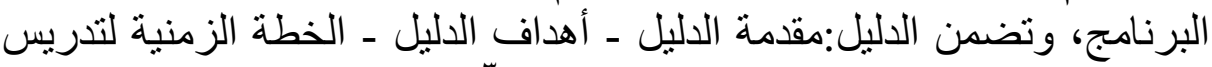

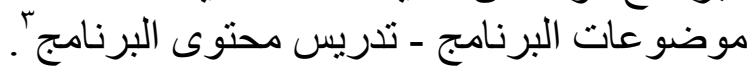

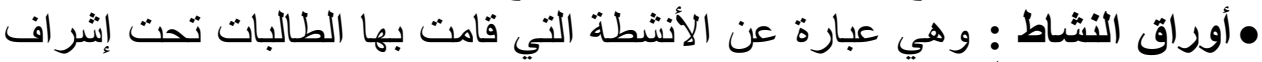
وتوجيه المعلم؛ ألمان. 
ثالثًا: بناء أدوات البحث، وتمثلت في: - - إعداد الاختبار التحصيلي، وفقا للخطوات التوات التالية:

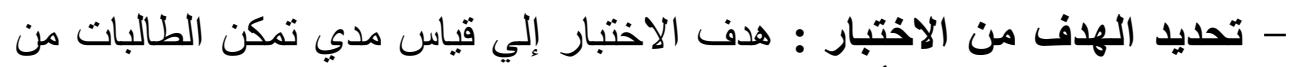

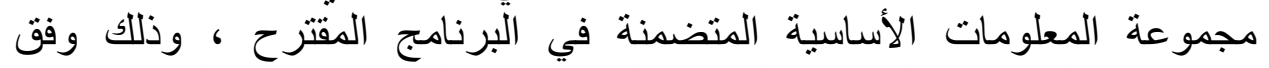

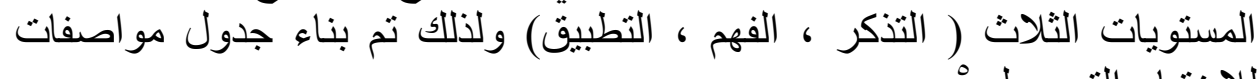
للإختبار التحصيلين.

- صياغة مفردات الاختبار: تم صياغة مفردات الاختبار في ضوء الإخ الأهداف

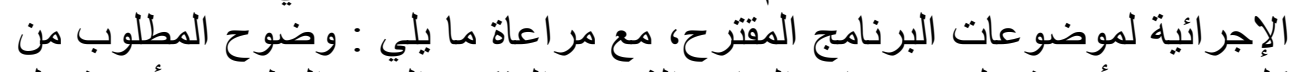

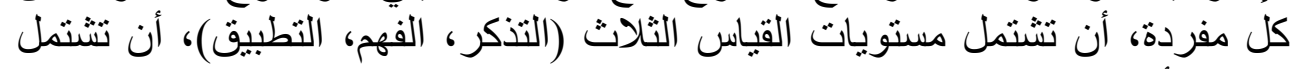

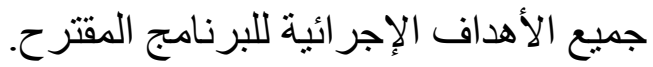

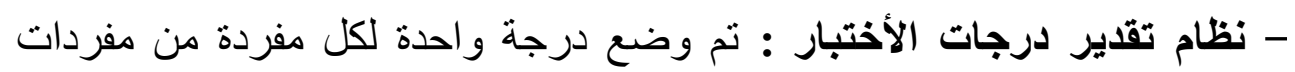

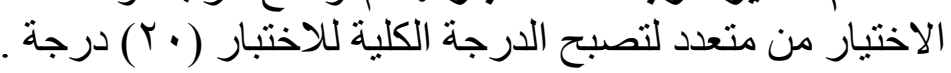

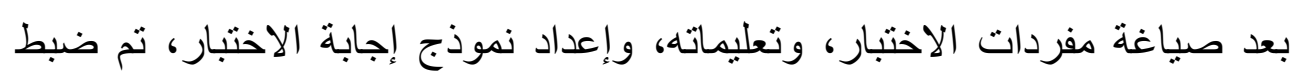

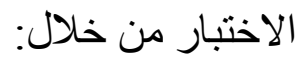
أ. التأكد من صدق الاخت منار: الآبار: تأكدت الباحثة من صدق الاتساق الداخلي للاختبار

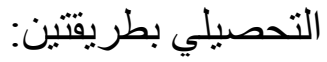

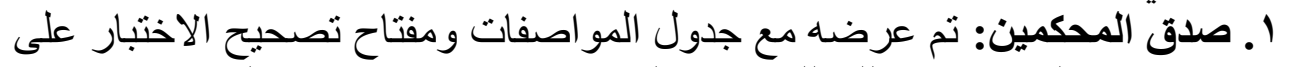

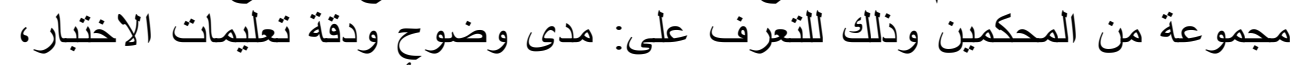

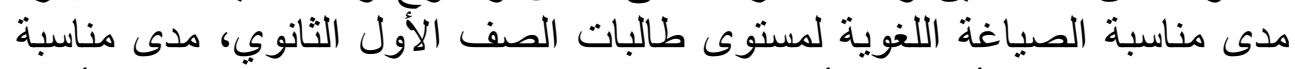

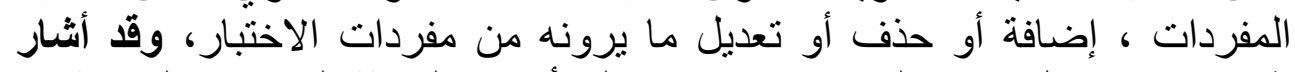

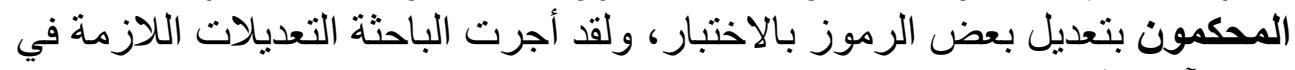
ضو Y.صدق الاتساق الداخلي للاختبار: تم حساب معامل الارتباط بين درجة كل مستوي

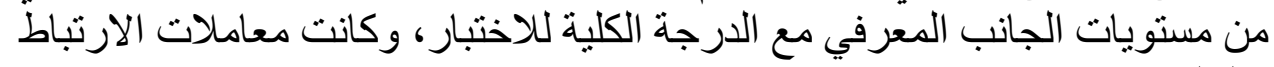

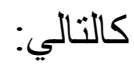
جذول (Y): يوضح معاملات الارتباط بين كل بعد والدرجة الكلية في الاختبار التحصيلي معامل الارتباط أبعاد الاختبار التحصيلي p

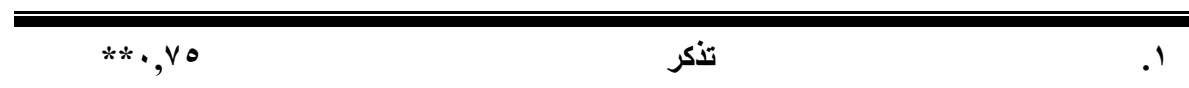

• ملحق (זّ): جدول مواصفات الاختبار التحصيلي. 


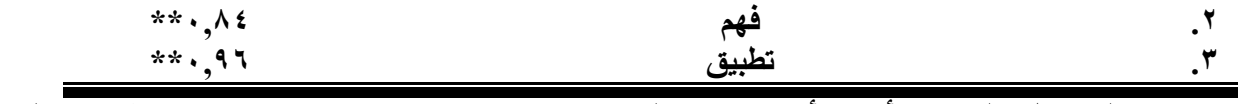
يتضح من الجدول السابق أن الأبعاد **دالة عند مستوى (1 · . . ) ، و هذا يعطي دلالة على ارتفاع معاملات الاتساق الداخلي، كما يشير إلى مؤشرات صدئ صدق مرتفعة وكافية

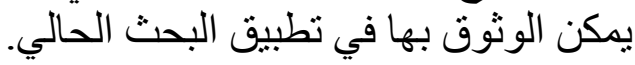
ب. بماب زمن وثباث الاختبار:

قامت الباحثة بدر اسة استطلاعية علي مجمو عة من ون طالبـات الصف الصف الأول الثانوي

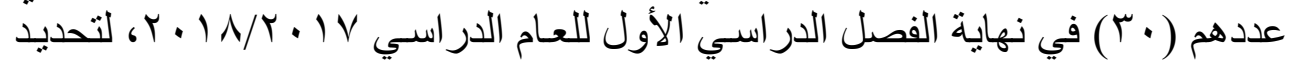

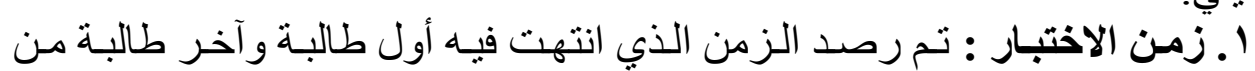
ما بلي: الإجابة عن أسئلة الاختبار وكان الزمن من هو ( • (9) دقيقة تقريبً.

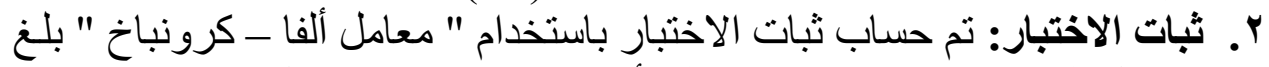

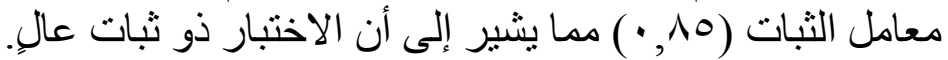

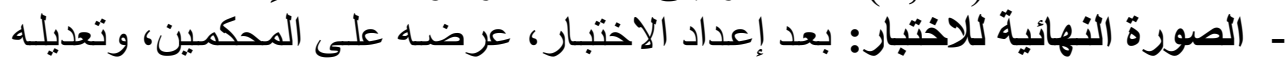
في ضوء مقترحاتهم، وبالتأكد من صدقه وثباته أصبح الاختبار صـالحأ للتطبيتق في صور تنه النهائبة. ثانياً : إعداد مقياس التفكير الجاتبي، وفقاً للخطوات التالية: - تحديد الهدف من المقياس: هدف المقياس إلي قياس مدي امتلاك طالبـات الصف الأول الثانوي لمهار ات التفكير الجانبي. ـ تحديـ أبعـاد المقبـاس: تـم تقسيم المقبـاس إلي م أبعـاد كل بعد بعبـر عن إحدي

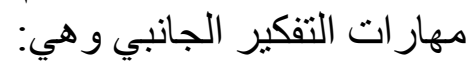

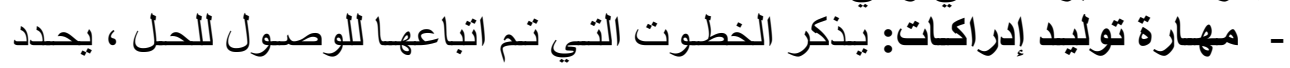

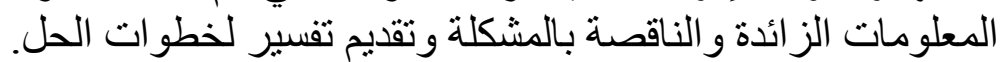

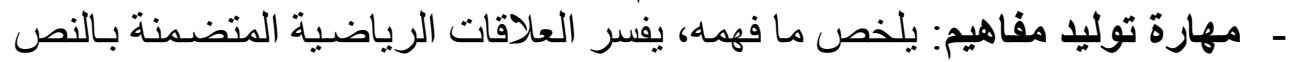
أو المثكلة ويتمكن من تسمية العمليات المستخدمة في حل المشكلة الرياضية.

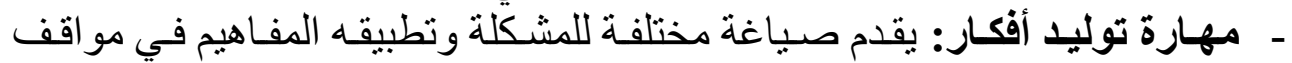

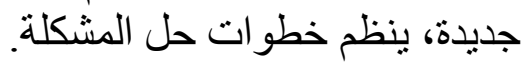

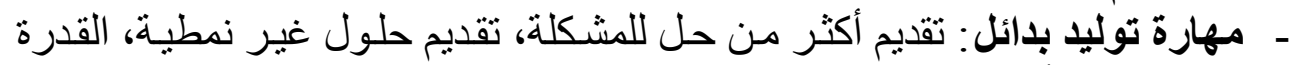
علي استدعاء الأفكار. - مهارة توليد إبداعات: إيجاد حلول مبدعة لمشكلات غير مألوفة. 


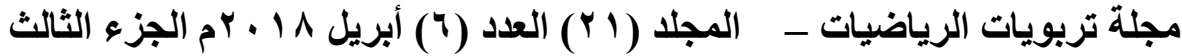

ويوضح ذلك جدول مو اصفات مقياس مهار ات التفكير الجانبي التالي جدول (r): جدول مول مواصفات مقياس مهارات التفكير الجانبي.

\begin{tabular}{|c|c|c|c|c|c|c|c|c|c|c|c|c|c|c|c|c|c|}
\hline כ: & $\bar{y} \bar{y}$ & \multicolumn{14}{|c|}{ الأسئلة } & مهارات التفكير & \\
\hline & & $\bar{m}$ & $\overline{4}$ & $\sqrt{1}$ & $=$ & ? & $\rightarrow$ & $>$ & $<$ & $\pi$ & - & m & 7 & 1 & 1 & الجانبي & r \\
\hline$r^{1, \varepsilon}$ & $r$ & & & & $*$ & & & & & & & $*$ & & & * & جهدئسةرة إدراكسات & .1 \\
\hline r $1, \varepsilon$ & $r$ & & * & $*$ & & & & & $*$ & & & & & & & 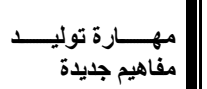 &.${ }^{\prime}$ \\
\hline$r 1, \xi$ & $r$ & & & & & * & & & & & & & $*$ & $*$ & & جهايدة توليد أفكار &.$r$ \\
\hline$r_{1, \varepsilon}$ & $r$ & * & & & & & & & & $*$ & $*$ & & & & & مهارة توليد بدائل &..$^{\varepsilon}$ \\
\hline $1 \leqslant$ & r & & & & & & * & $*$ & & & & & & & & 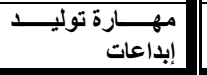 & $0^{\circ}$ \\
\hline $1 \ldots$ & $1 \varepsilon$ & $T$ & 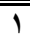 & $\overline{1}$ & 1 & 1 & 1 & 1 & 1 & 1 & 1 & 1 & $\overline{11}$ & 1 & 1 & المجــــوع & \\
\hline
\end{tabular}

ـ تقدير درجات المقياس: قُرت درجة المقياس العظمي (• ع) والدرجة الصغري

بعد صياغة مفردات المقياس، وتعليماته ، تم ضبط المقياس من خلال: أ. التأكد من صدق المقياس: تأكدت الباحثة من صدق الاتساته فئن الداخلي لمقياس مهار ات التفكير الجانبي بطريقتين:

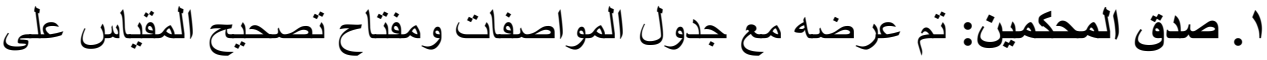

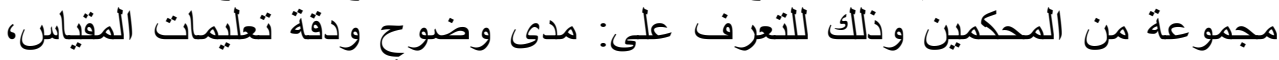

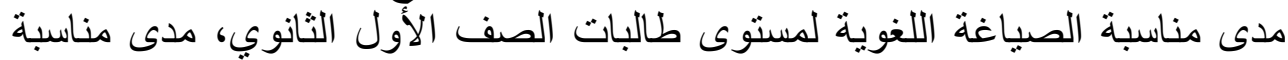
المفردات لقياس قدرة طلاب الصف الأول الثانوي على استخدام مهارات التهات التفكير

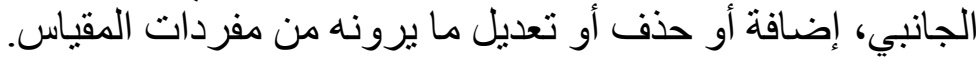

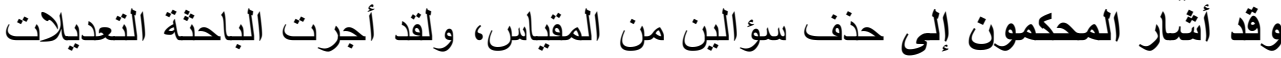

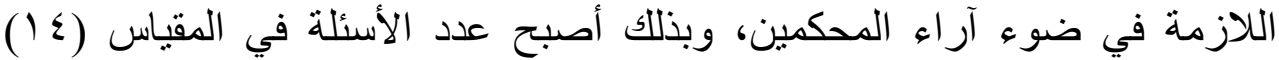
سؤ الا. Y.صدق الاتساق الاخلي للمقياس: تم حساب معامل الارتباط بين درجة كل مهارة

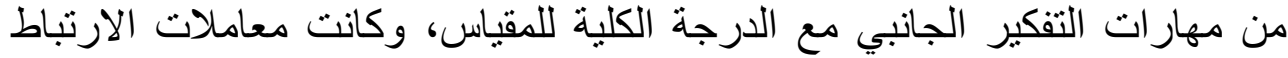

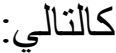

جدول (؛ ): يوضح معاملات الارتباط بين كل بعد والارجة الكلية في مقياس مهارات التفكير الجانبي 


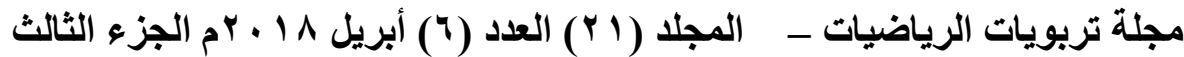

\begin{tabular}{|c|c|c|}
\hline$* *, y r \mu$ & توليد إدراكات جديدة & .1 \\
\hline$* *,, \vee Y_{1}$ & توليا مفاهيم جديدة &.$r$ \\
\hline$* *,, \circ \vee 4$ & توليد أفكار جديدة &.$r$ \\
\hline$* *,, 717$ & توليد بدائل جليدة &.$\varepsilon$ \\
\hline$* *,, 009$ & توليد" إبداعات جديدة & .0 \\
\hline
\end{tabular}

يتضح من الجدول السابق أن الأبعاد **دالة عند مستوى ( ( . • )، وهذا بعطي دلالة

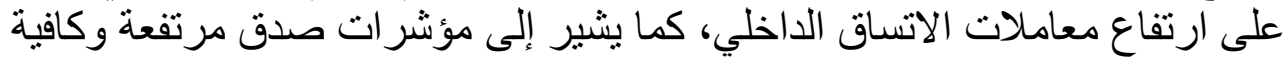

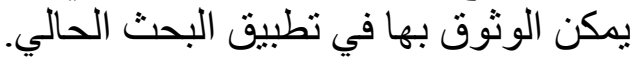
ب. ساب زمن ومعامل ثبات المقياس:

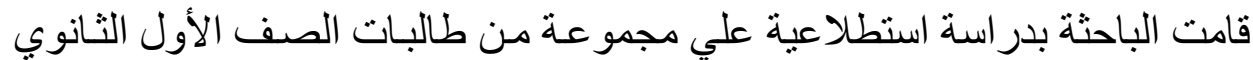

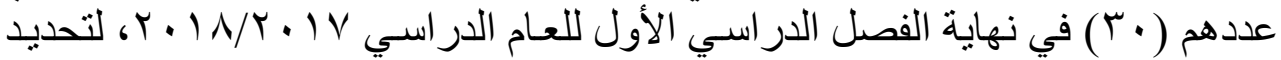
ما يلي:

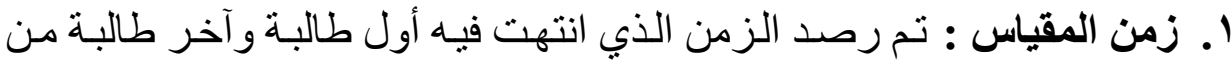

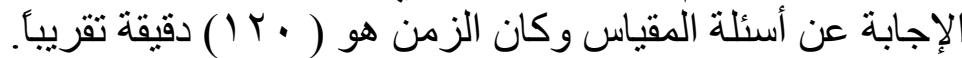

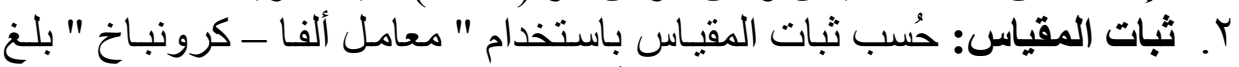

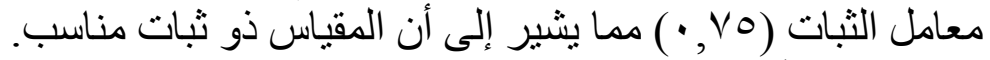

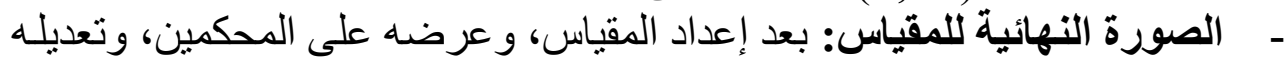

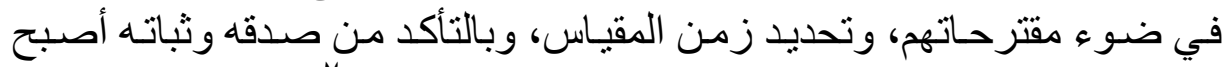

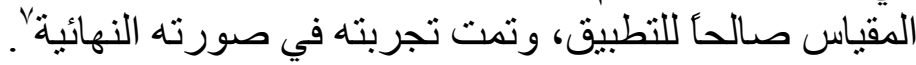

ثالثًا: إعداد مقياس حب الاستطلاع: وفقاً للخطوات التالية: - تحديد الهُف من المقياس: هدف المقياس إلي قياس مستوي حب الاستطلاع لدي طالبات الصف الأول الثانوي.

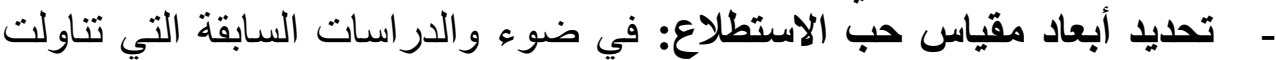

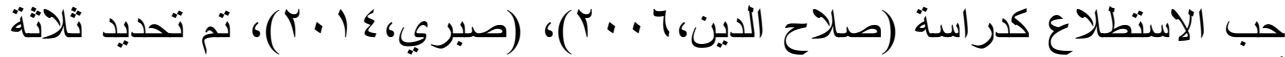

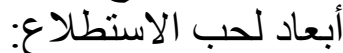

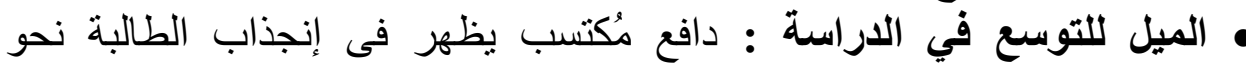

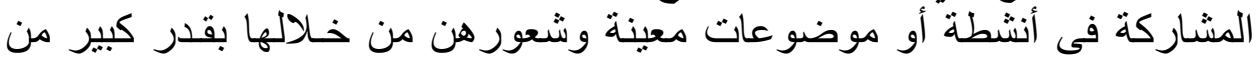

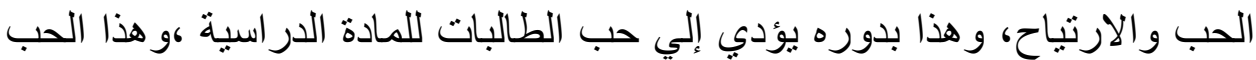

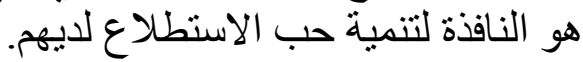


• الاستمتاع بالتعلم: رغبة الطالبة بالاستمرار في الانجاز والاندماج، وتثقييم المو اقف بطريقة إيجابية، من خلال المشاعر الوجدانية التئية تعبر عن المتعة المرتبطة الأنة بالتعلم. الإفعية للإنجاز: وهي الرغبة والطاقية والطاقي التي تمتلكها الطالبة والتي تدفعها للانتباه

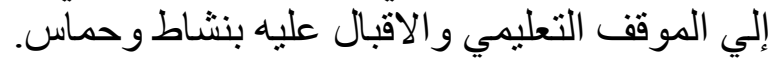

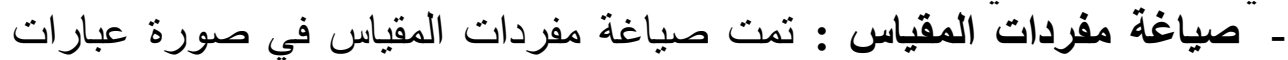

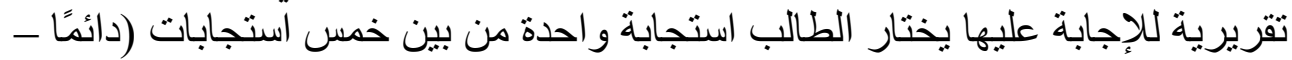

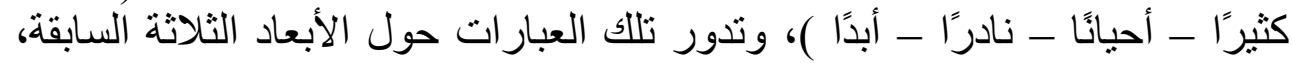

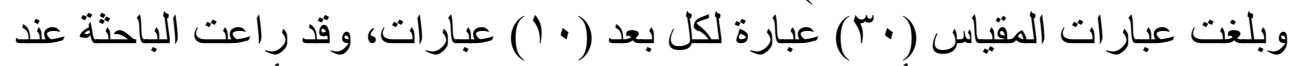

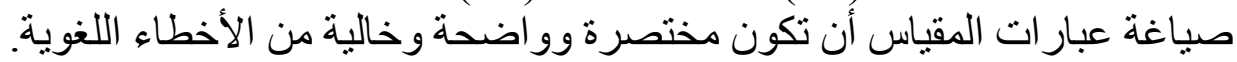

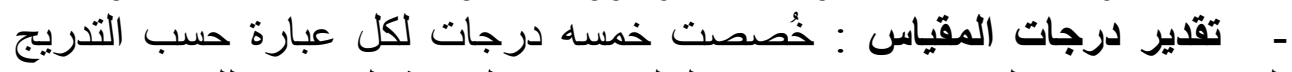

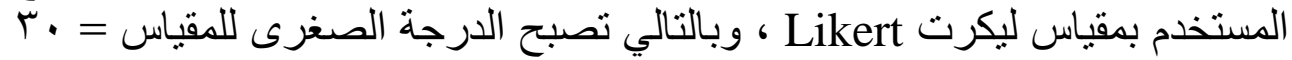

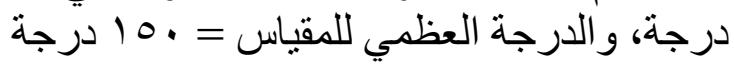

- بعد صياغة مفردات المقياس، وتعليماته، تم ضبط المقياس من خداس خلاسل:

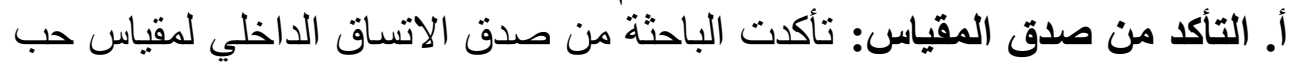

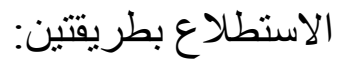
ا ـ صدق المحكمين: حيث تم عرضنه على مجموعة من المحكمين وذللك للتعرف

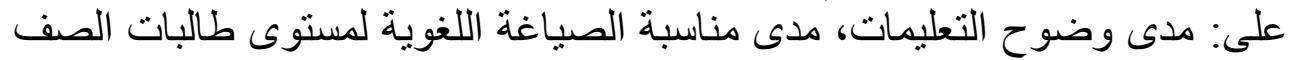

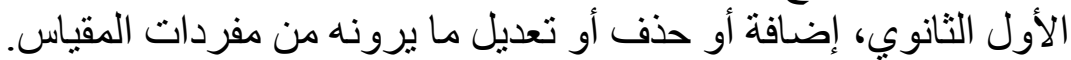

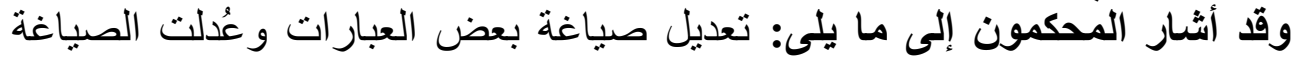
- أشعر بفضول علمي لمعرفة وتعلم المزيد حول الرياضيات العصرية، أصبحت :

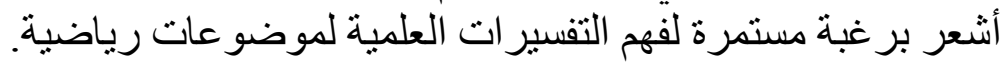

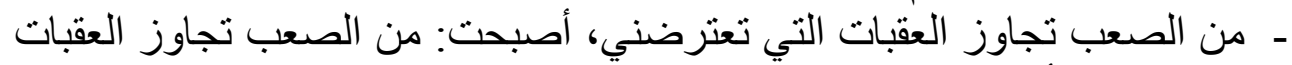

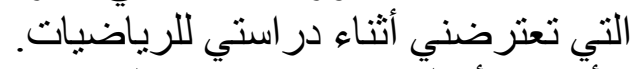

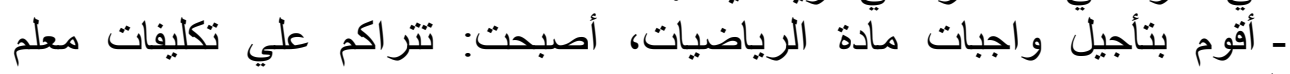
الرياضيات.

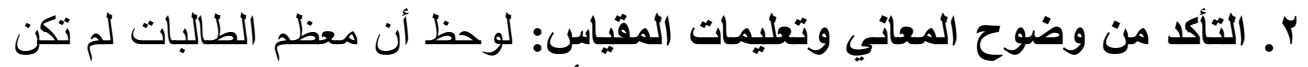

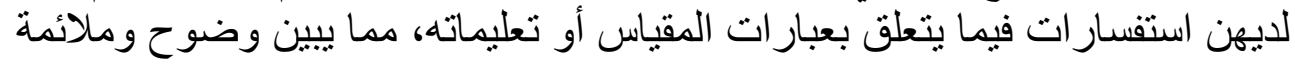
بنود المقياس ومناسبتها. 


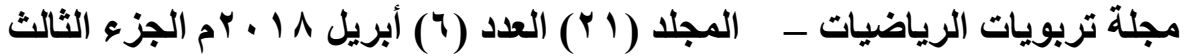

ץ. صدق الاتساق الداخلي للمقياس: تم حساب معامل الارتباط بين درجة كل بعد من الإن

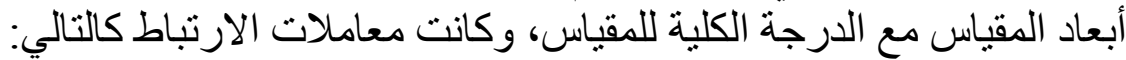
جدول (0): يوضح معاملات الارتباط بين كل بعد والارجة الكلية في مقياس حب الآستطلاع معامل الارتباط أبعاد مقياس فاعلية الذات

\begin{tabular}{|c|c|c|}
\hline$* *, 799$ & الميل للتوسع في الدراسة & 1 \\
\hline$* *, 719$ & الاستمتاع بالتعلم & r \\
\hline$* *, \bullet \varepsilon$ & دافعية الإنجاز & $r$ \\
\hline
\end{tabular}

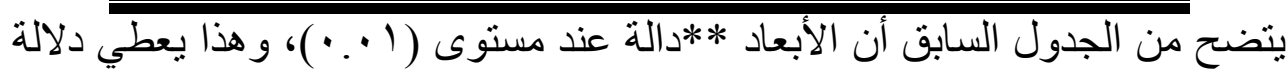

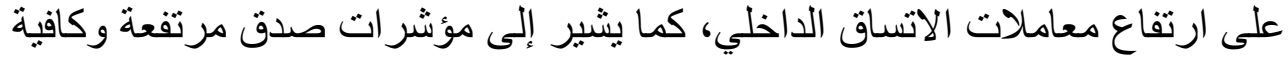

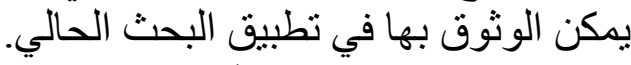

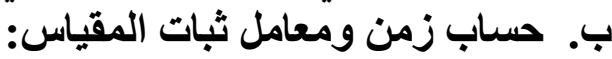

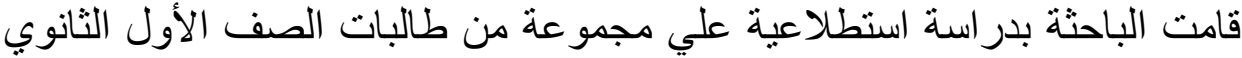

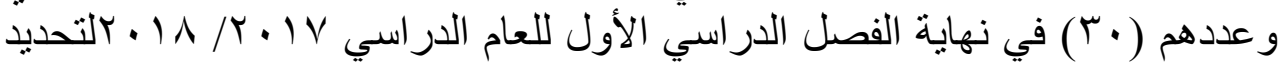
ما يلي: ا ـ تحديد زمن المقياس: تم رصد الزمن الذي انتهت فيه أول طالبة و آخر طالبة من

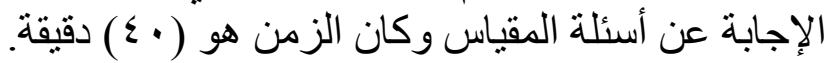

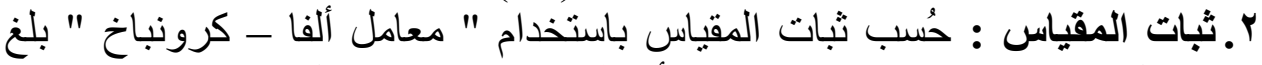

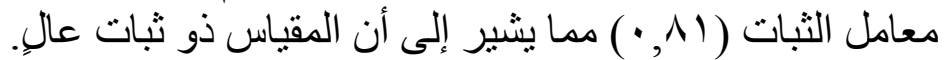

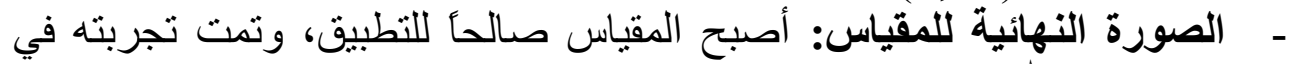

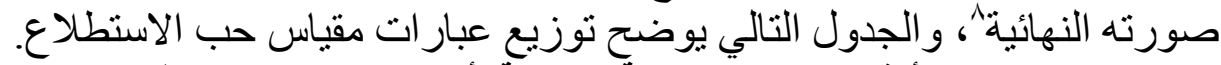

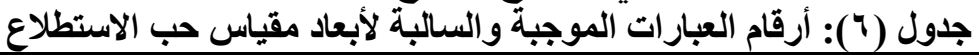

\begin{tabular}{|c|c|c|c|}
\hline المجموع & أرقام العبارات السالبة & أرقام العبارات الموجبة & الأبعاد الرئيسية للمقياس \\
\hline 1. & $1 \cdot-\Lambda_{-}-\tau_{-} \varepsilon-r$ & $q_{-} V_{-} \theta_{-} r_{-} 1$ & الميل للتوسع في الدراسة \\
\hline 1. & $r-1 \Lambda_{-}\left|\tau_{-}\right| \varepsilon_{-} \mid r$ & $1 q_{-}\left|V_{-}\right| \theta_{-}\left|r_{-}\right| 1$ & الاستمتاع بالتعلم \\
\hline 1. & $r \cdot-Y \wedge_{-} Y Y_{-} Y \leqslant-Y Y$ & $r Q_{-} r V_{-} r \theta_{-} r r_{-} r 1$ & دافعية الإنجاز \\
\hline$r$. & 10 & 10 & مجموع العبارات \\
\hline
\end{tabular}

^ ملحق(ף):مقياس حب الاستطلاع. 


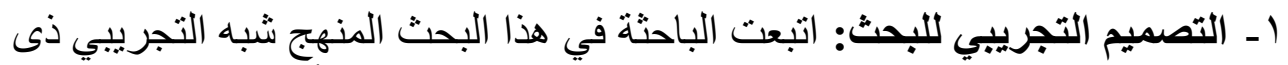

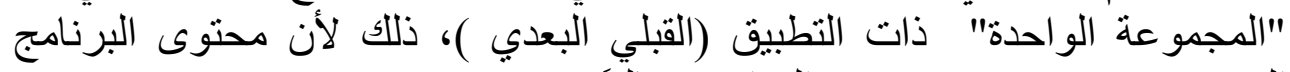

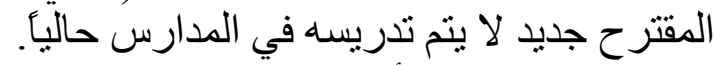
r- التطبيق القبلي لأداتي التقويم: طبقت التباحثنة الاختبار التحصيلي ومقياس التفكير

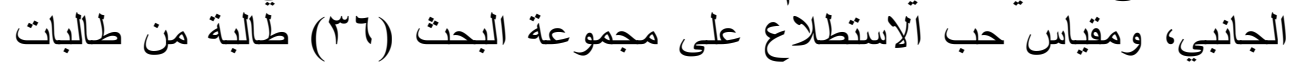
الصف الأول الثانوي؛ وذلك بهدف الحصول علي المعلومات القبلية لمجمو عة البحثي.

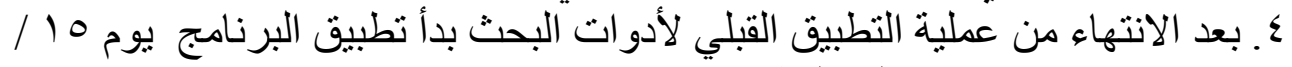

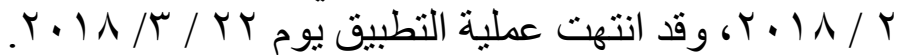

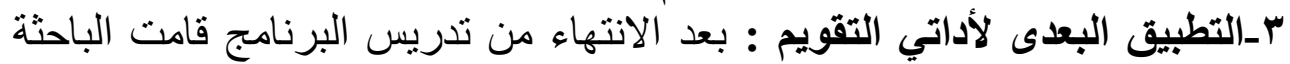

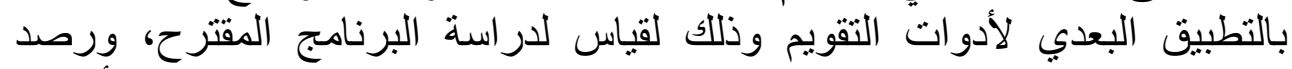

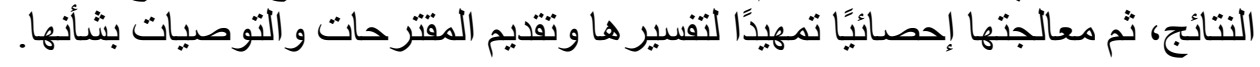

\section{تتائج وتفسير ها، ومناقشتها، وتوصياتها ، ومقترحاتها:}

تم رصد درجات الطالبات مجموعة البحث قبل وبعد تدريس البرنامج المقترح،

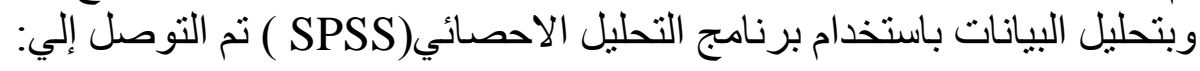
أولاً: نتائج تطبيق الاختبار التحصيلي: ينص الفرض الأول على إنه:"يوجد فرق دالئ دال

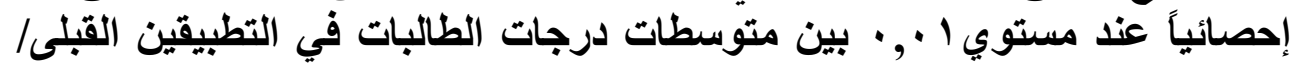

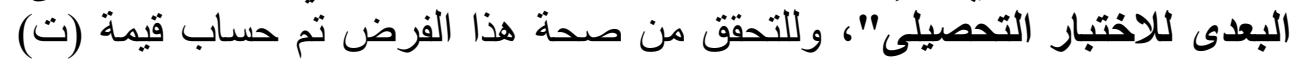

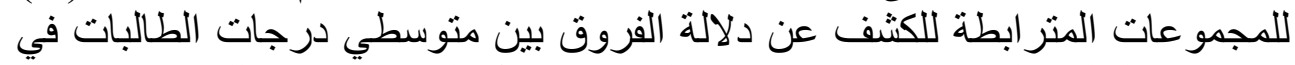

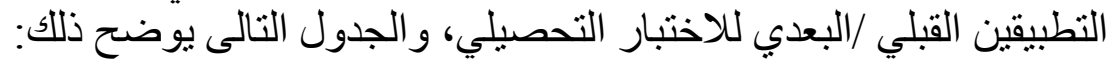
جدول (V): قيم (ت) للفرق بين متوسطي درجات الطالبات فى التطبيقين القبلى /البعدى للاختبار التحصيلى دوجي.

\begin{tabular}{|c|c|c|c|c|c|c|}
\hline حجم التأثير & مستوى الدلالة & قيمة ( ت ) & الحرية & الانحريارى افى & الحستوسط & التطبيق \\
\hline $9 \vee$ & دال عند 1 •.. & $r_{0, \wedge}$ & ro & $\begin{array}{l}1, \cdot v \\
r . \cdot 1\end{array}$ & $\begin{array}{l}1, Y Y \\
10,9\end{array}$ & البقلى البعى \\
\hline
\end{tabular}

* قيمة (t) المحسبوبة دالة عند مستوي 1 •, 


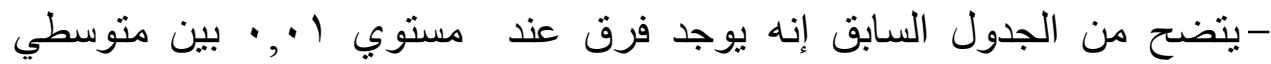

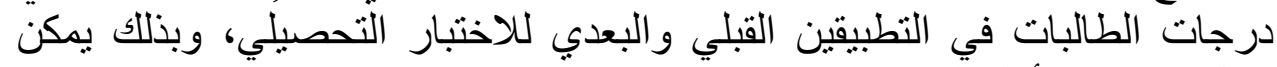
قبول الفرض الأول للبحث.

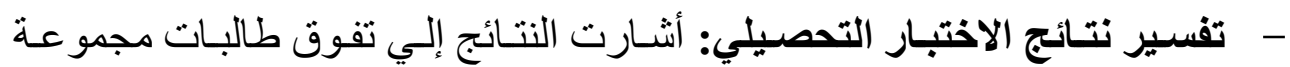

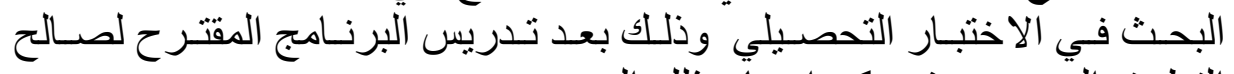
التطبيق البعدي حيث يمكن إرجاً ذلار ذلك إلي:

- طبيعة الرياضيات الفازية وارتباطها بكل ما يحيط بالفرد فى الطبيعة وتكنولوجيا

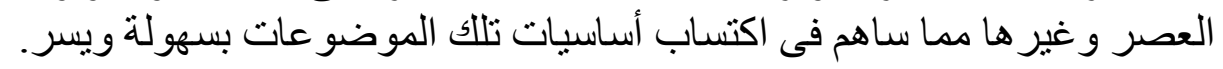

- إنتقال الطالبات من دراسة الرياضيات التقليدية إلى الرياضيات الفازية، جعلت الطالبات تستشعر حيوية الرياضيات ودينالينامكيتها.

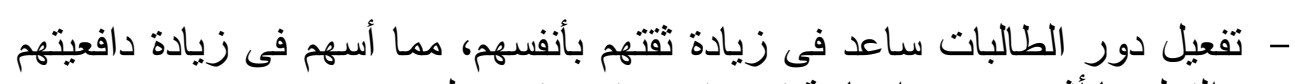

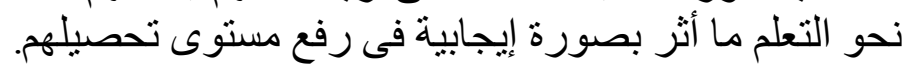

- استخدام عديد من الأنشطة أثناء التدريس وتنو عها كان لها أثر كبير في مو اجهة

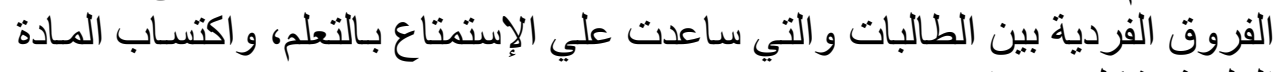
العلمية بشكل يسير ا.

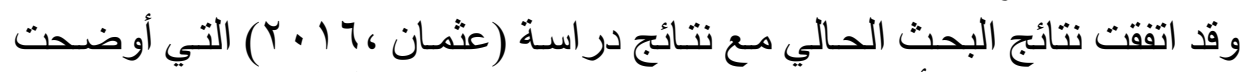

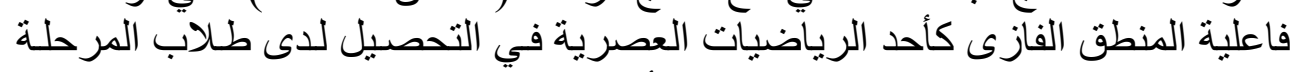

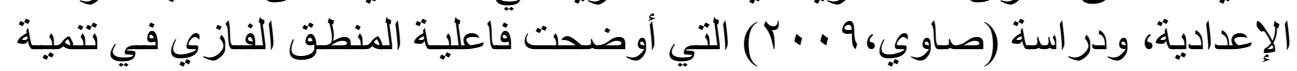

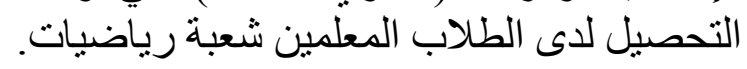

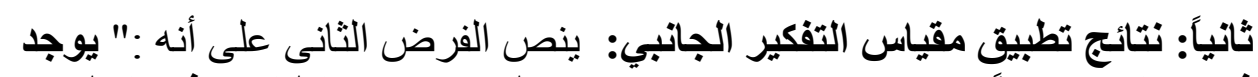

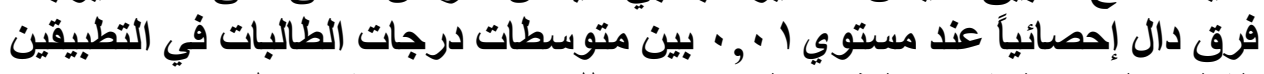

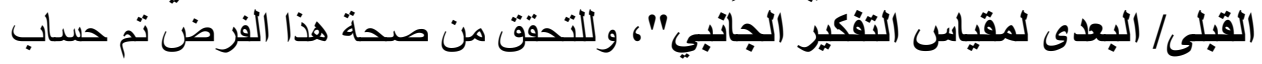

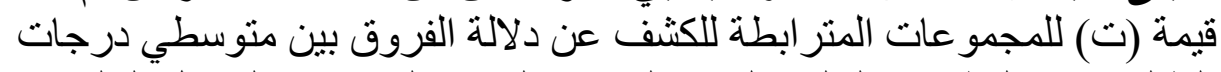

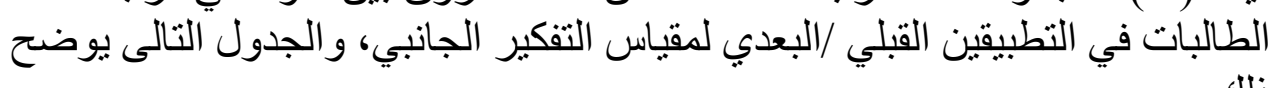

جدول (^) : قيم (ت) للفرق بين متوسطي درجات الطالبات فى التطبيقين

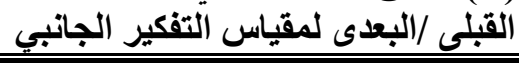

\begin{tabular}{|c|c|c|c|c|c|c|}
\hline \multirow{2}{*}{ حجم التأثير2 } & قيمة (t)" & & & & & \multirow[b]{2}{*}{ أبعاد المقياس } \\
\hline & المحسوبة & ع & ip & $\varepsilon$ & מ & \\
\hline
\end{tabular}




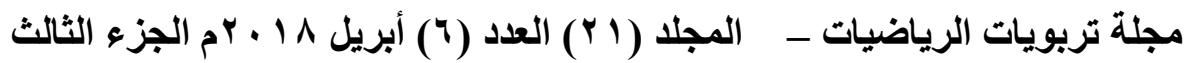

\begin{tabular}{|c|c|c|c|c|c|c|}
\hline •, ג & *Ir,q & 1,1 & 7,17 & 1.0 & $\bar{P} Y, Y V$ & توليا إدراكات جديدة \\
\hline$\cdot, V_{0}$ & $* 1 \cdot, \varepsilon$ & $1, r$ & 0 & 1,8 & $1, v$ & توليد مفاهيم جديدة \\
\hline$\cdot, \wedge r$ & $*$ & $1, r$ & $\bullet, r$ & $1, r$ & 1,07 & توليد أفكار جديدة \\
\hline$\cdot, \wedge 0$ & $* 1 \leqslant, 7$ & $1,7 \mathrm{~V}$ & $7, r$ & $r, \cdot \varepsilon$ & r,19 & توليد بدائل جديدة \\
\hline$\cdot, \wedge \varepsilon$ & $* 1 r, 1$ & $1, \varepsilon$ & $\varepsilon, 7$ & 1,7 & $\cdot, \vee_{7}$ & توليد إبداعات جديدة \\
\hline$\cdot, 9 \leq$ & $r r, \Lambda$ & $r, \wedge$ & $r V, r$ & $\varepsilon, 0$ & $\Lambda, 0$ & المقياس ككل \\
\hline
\end{tabular}

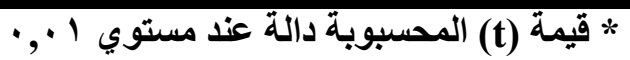

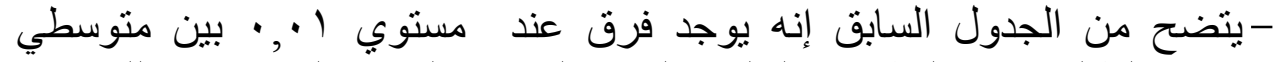

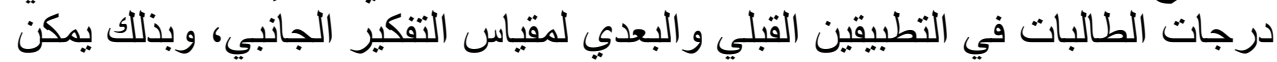
قبول الفرض الثاني للبحث.

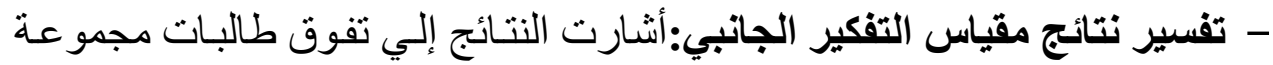

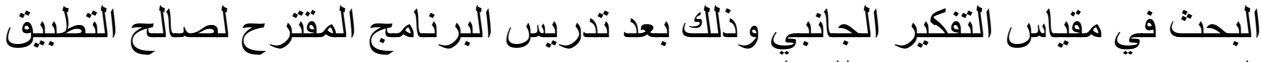
البعدي حيث يمكن إرجاع ذللك إلي:

- - التفكير الرياضى الخاص بالرياضيات الفازية ساعد على تنمية مهار ات اتل التفكير

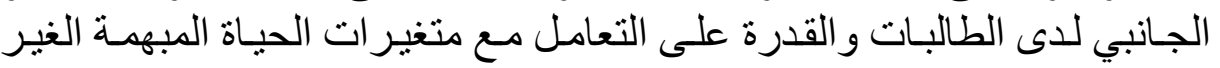

$$
\text { محددة و الغير و اضحة لـ الطيات }
$$

- - مرونة الرياضيات الفازية في معالجتها لغموض الواقع كان الفيز له دور في تغيير

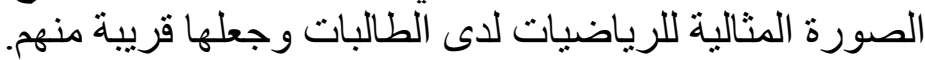

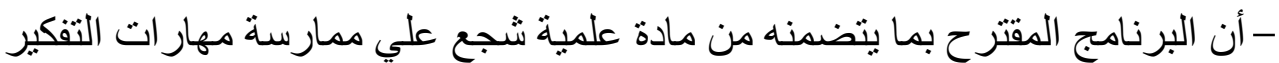

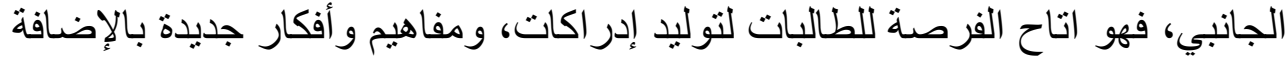
لتولبد بدائل، مما ساهم في الوصول الفئ إلى مستويات أعلى من التفكير الجانبي.

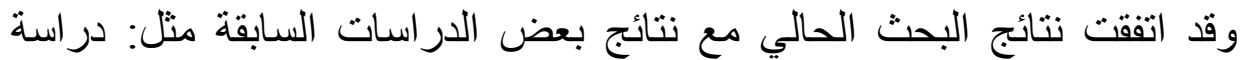

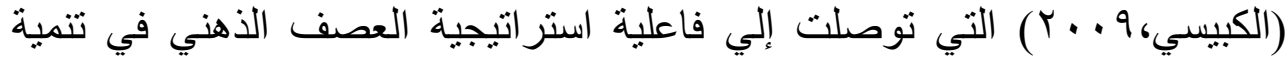

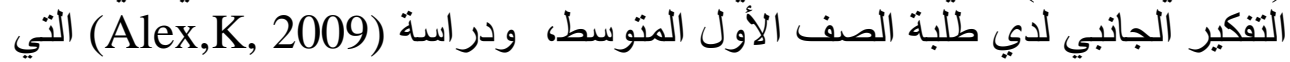

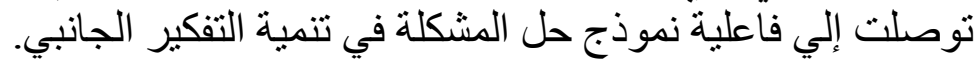

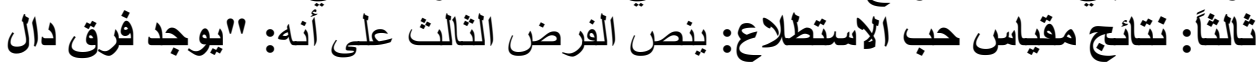

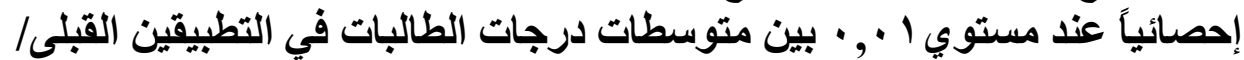

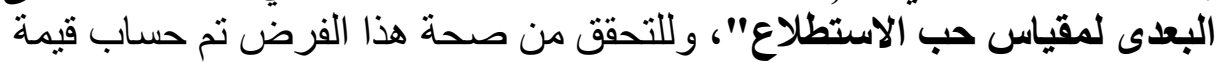

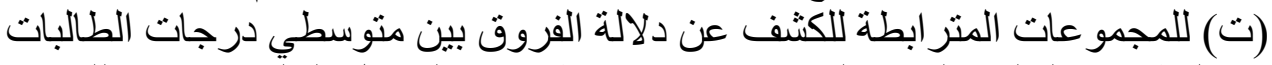

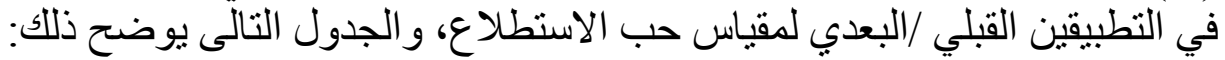
جدول (9): قيم (ت) للفرق بين متوسطي درجات الطالبات في التطبيقين القبلي/البعدى لمقياس حب الاسنطي درجلاع. 


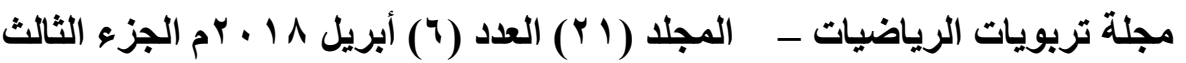

\begin{tabular}{|c|c|c|c|c|c|c|}
\hline حجم & قيمة (t)" & \multicolumn{2}{|c|}{ التطبيق البعدي } & \multicolumn{2}{|c|}{ التطبيق القبلي } & \multirow{2}{*}{ أبعاد المقياس } \\
\hline التأثير & المحسوبة & ع & קז & ع & מمו & \\
\hline$\cdot, \vee 9$ & *1 $1 \leq, 9$ & $\varepsilon, V$ & $\leqslant 1, \wedge$ & 7,1 & $r \cdot, 0$ & الميل للتوسع في الدراسة \\
\hline$\cdot, 91$ & * $1 \leqslant, r$ & $\varepsilon, r$ & $r v, v$ & $0, \varepsilon$ & $r q, q$ & الاستمتاع التعلم" \\
\hline$\cdot, 9 \leq$ & $* 11,19$ & $\varepsilon$ & $r \varepsilon, q$ & $\varepsilon, \wedge$ & $r v, r$ & الدافعية للإنجاز \\
\hline$\cdot, 9 V$ & $r r, 0$ & 1,0 & $11 \leqslant, 0$ & $1 \cdot, 1$ & 10,17 & المقياس ككل \\
\hline
\end{tabular}

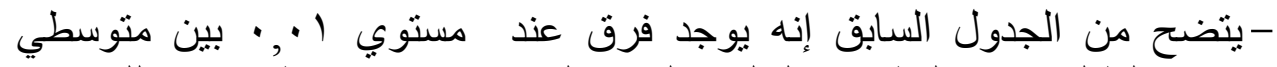
درجات الطالبات في التطبيقين القبلي و البعدي لمقياس حب الني الاستطلاع، وبذللك يمكن قبول الفرض الثالث للبحث.

ـ تفسير نتائج مقياس حب الاستطلاع: أثـارت النتائج إلي تفوق طالبات مجمو عـة

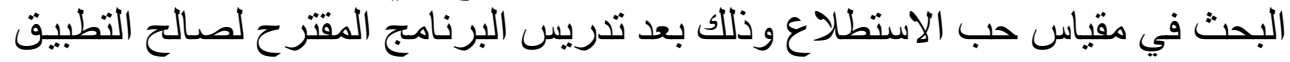
البعدي حيث يمكن إرجاع ذللك إلي:

- تلوع الإستراتيجيات التدريسية المستخدمة، ساعدت في إثناعة مناخ مشجعا للطالبات للتوصل إلي حلول مبتكرة دون التقيد بخطوات التفيكة التفير التقليدى.

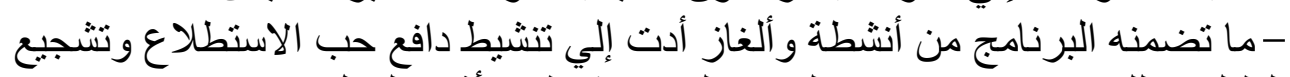

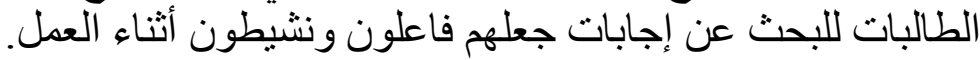

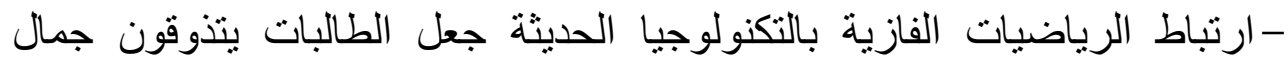

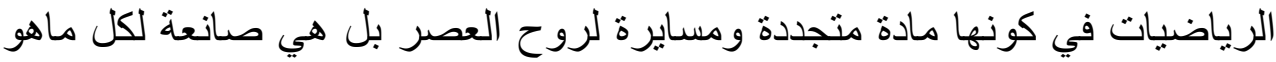
عصري وجديد.

• وقد اتفقت نتائج البحث الحالي مع نتائج بعض الدراسات السابقة مثل:دراسة

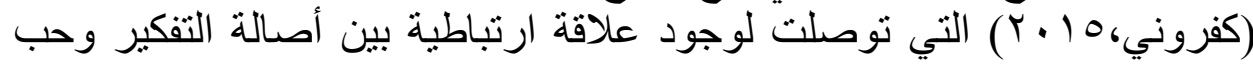

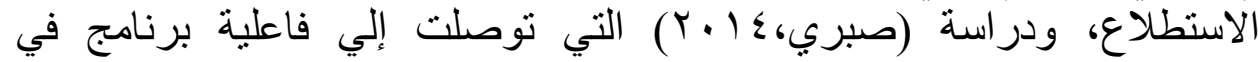

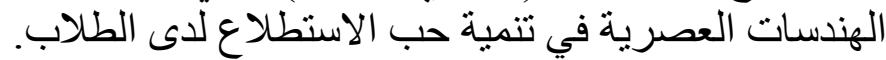

\section{توصيات البحث:}

في ضو ء مشكلة البحث وما توصل إليه من نتائج نوصي الباحثة بما يلي: - تضمين موضوعات الرياضيات الفازية في المقررات الدراسية للمرحلة الثانوية وباقي المراحل الدراسية بما يتناسب مع كل مرحلة. 
- الإهتمام بتنمية الجوانب الوجدانية أثناء عملية التعليم وعدم التركيز فقط على الجو انب المعرفية.

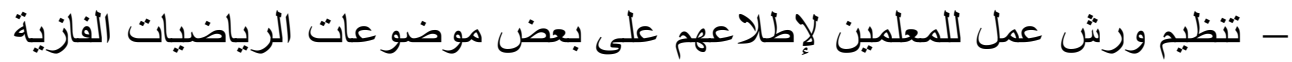
كونها رياضيات عصرية لها تطبيقات تكنولوجية ولية واسعة.

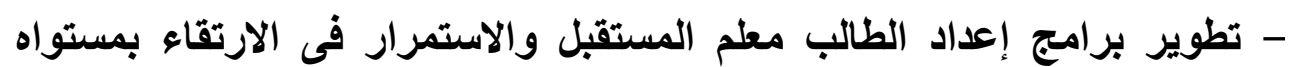

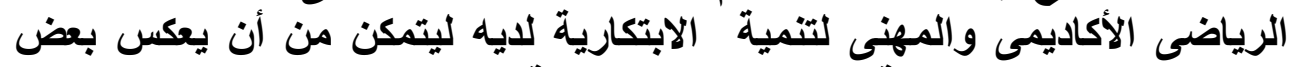

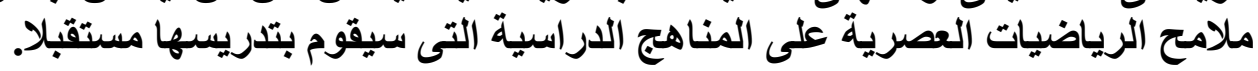
- استخدام طرق و أساليب متنو عة تساعد في تنمية حب الاسنطلاع لدي التعلمين في عمليتي تعليم وتعلم الرياضيات لجميع المر احل التعليمية.

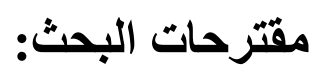
في ضوء ما توصل إليه البحث الحالي من نتائج ، تقترح الباحثة إجراء البحوث

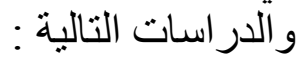

- در اسة فاعلية وحدات في الرياضيات الفازية على تنمية أنواع مختلفة من التفكير. - در اسة أثر تضمين بعض موضو عات الرياضيات الفازية فى المقررات الدر اسية للمر احل المختلفة.

- إعداد بر امج في النظريات الرياضية المختلفة التي تناولت معالجة أنواع مختلفة

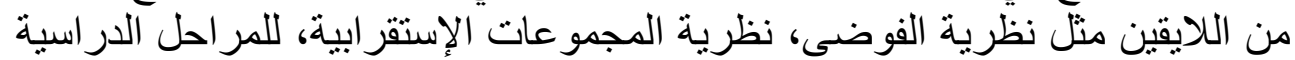
المختلفة بعد تبسيطها بما يتناسب من مع كل مرحلة.

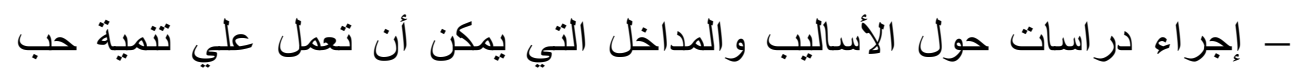
الاستطلاع لدي المتعلمين في المر احل التعليمية المختلفة.

ـ در اسة لتحديد الصعوبات التي تواجه دارسي الرياضيات في استخدام مهار ات التي التفكير الجانبي.

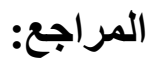

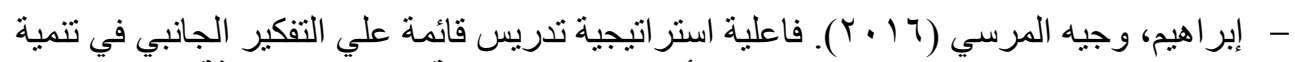

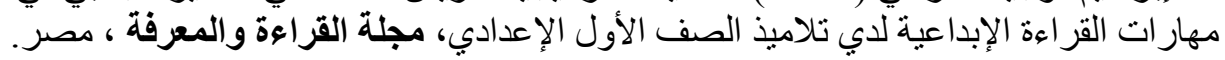




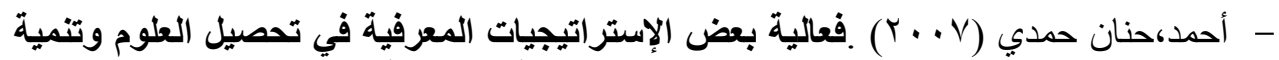

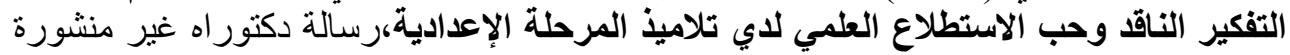
،كلية التربية جامعة طنطا.

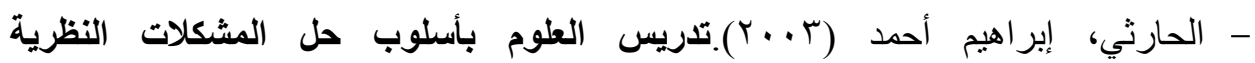
والتطبيق،ألرياض، التمكتبة الثقري.

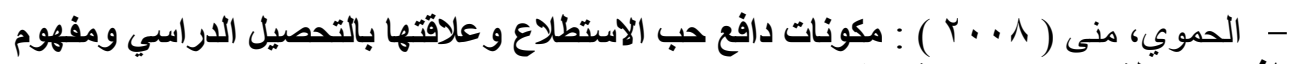

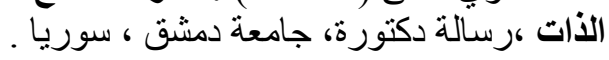

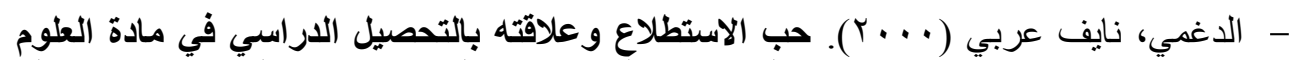

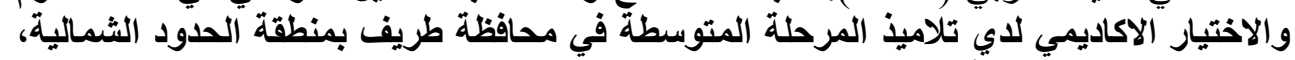

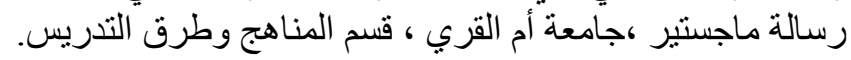

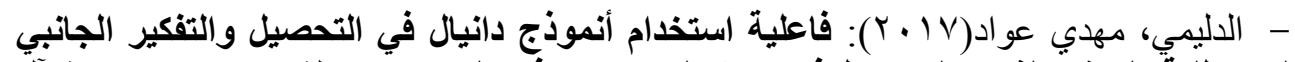

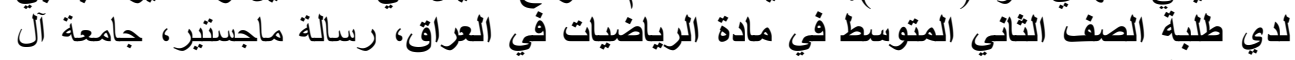
البيت، الآردن.

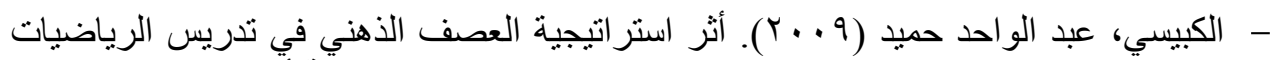

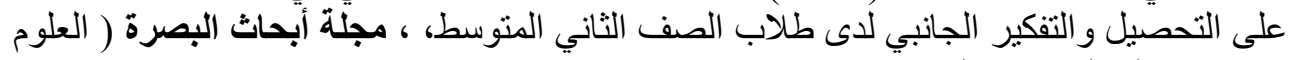

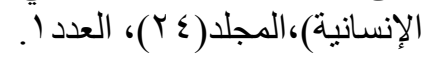

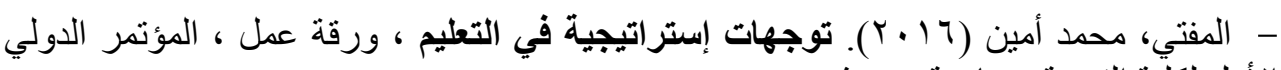

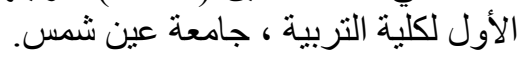

- النويهى، سهام ( ( . . ب): المنطق الغائم، كراسة علمية، القاهرة، المكتبة الآكاديمية.

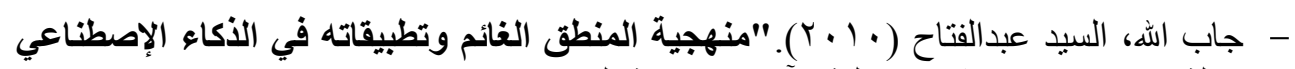
"،رسالة دكتور اه غير منشورة ،كلية الآداب، جامعة القية القاهرة.

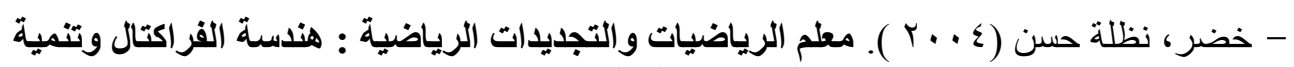

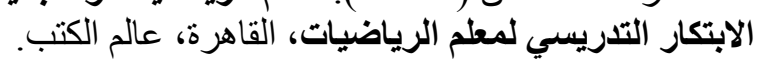

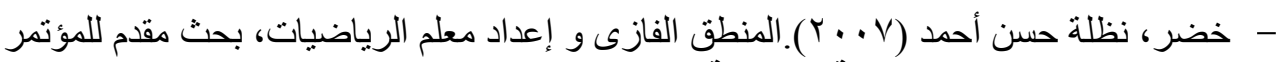

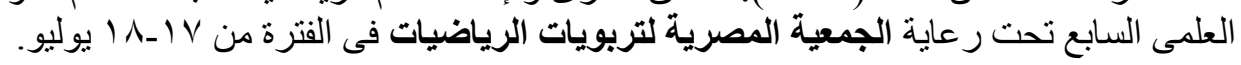

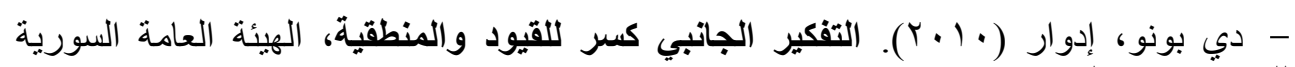

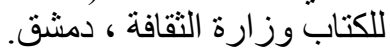

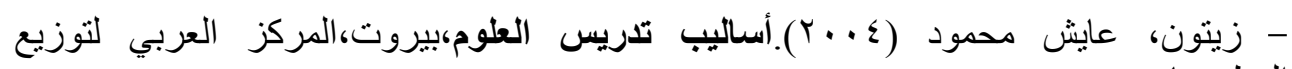
المطبو عات.

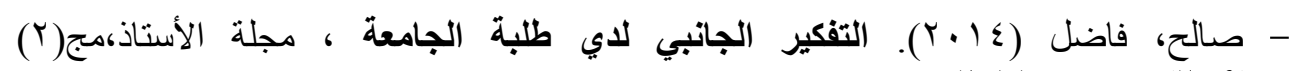

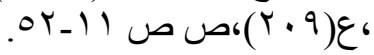




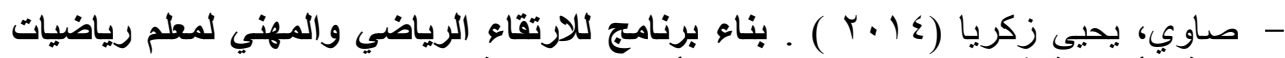

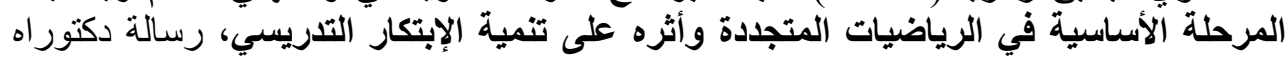

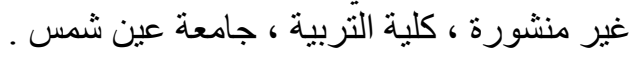

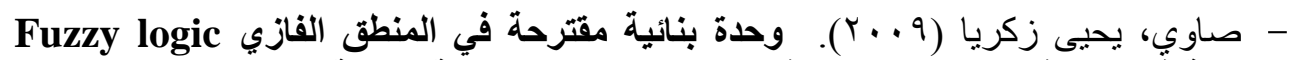

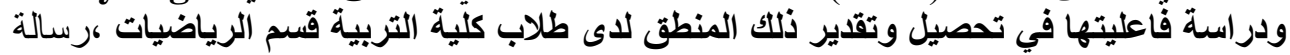

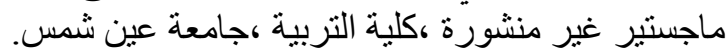

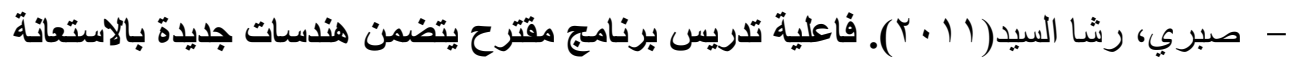

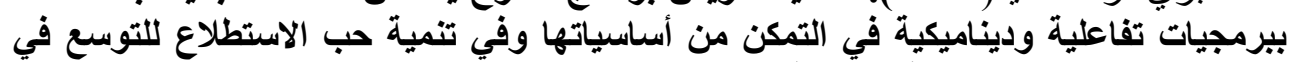

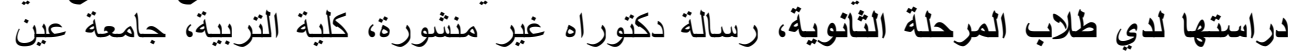

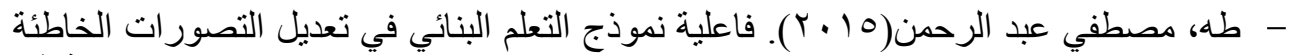

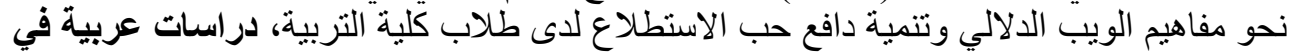

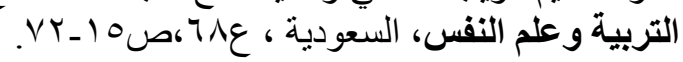

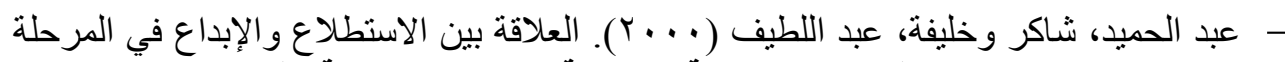

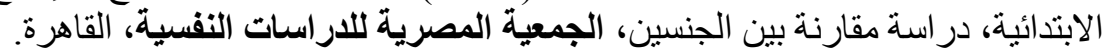

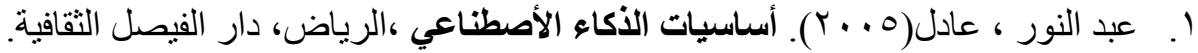

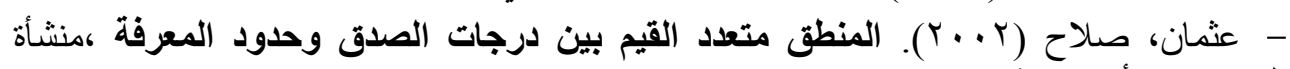
المعارف بالأسكندرية.

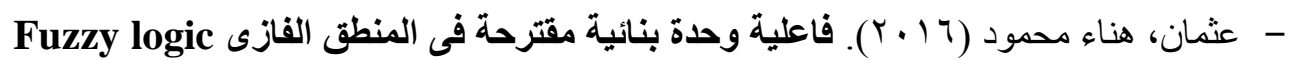

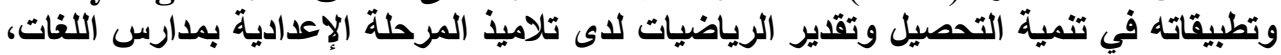

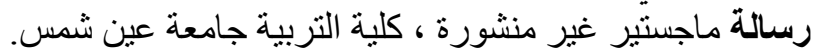

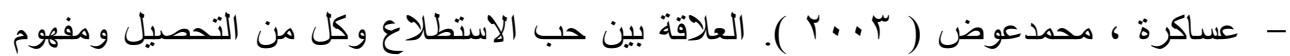

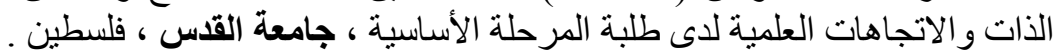

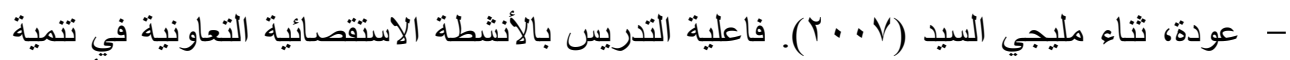

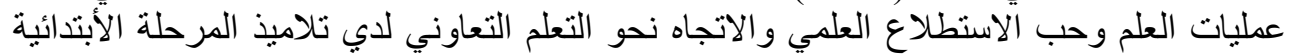

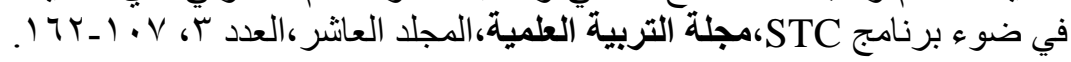

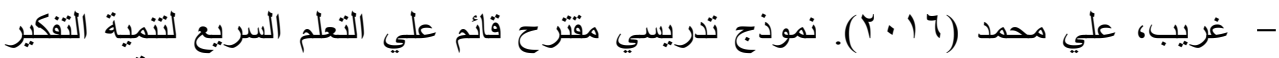

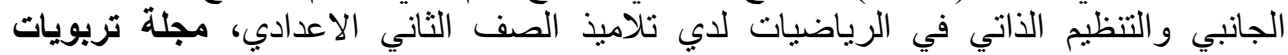

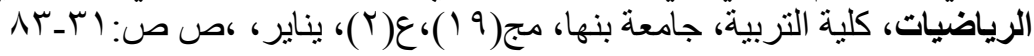

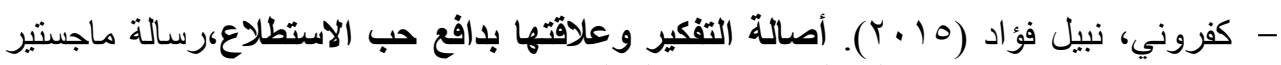
غير منشورة، جامعة دمشق، كلية التربية، قسم علم النفس.

- Alex, K. (2009):"Influence of Personal Preferred Creative ProblemSolving Style \&Organizational Creativity Factors on Types of 
Lateral Thinking "Degree (Ph.D), The Senate of University Putra Malaysia, Psasir, Upm. Edu.My/222371 /A

- Buljac, Andrija (2014). LATERAL THINKING: CREATIVITY STEP BY STEP, FSB: Uvod u znanstveno istraživački rad UDC 62:65.01:159.954

- Imran, B.M\&Sofyan, M.M (2012).Fuzzy Identification of Geometric Shapes, CCSIT. 2012,part3 , LNICST86 P.269-279

- Bussakorn (2009) : curiosity based learning, Chulaiongkorn university sumrogthong,http://www.thailandpod.net/conf_resource/OralPresentation/o $\underline{\text { 8.pdf }}$

- De Bono, E. (1990). Lateral Thinking: a textbook of creativity. Penguin Books.

- De Bono, E. (2015).Lateral thinking, available at: http://leading2learn.ca/21st century_learning/keys_to_success/resources/debono_lateral_thinking.pdf

- Deb, rosenfeld (2007). capturing, sustaining, and transferring curiosity, education development center division of mathemtics,learning,and teaching newton, ma 02458http://www2.edc.org/thinkmath/lib/2007_Presentations/NCTM2007_ Curiosity_DR.pdf

- Garrido, A. (2012).A Brief History of Fuzzy Logic, BRAIN. Broad Research in Artificial Intelligence and Neuroscience, Volume 3, Issue 1, February, ISSN 2067-3957 (online), ISSN 2068 - 0473

- George, Mary (2006). Fuzzy Mathematics-Application in Economics, Campus Books, New Delhi.

- Jill Jesson (2012). Developing Creativity in the Primary School. Berkshire: Open University Press.

- John Harris (2006). Fuzzy Logic Aplications in Engineering Science, springer, Netherlands.

- Kwang H. Lee (2005). First Course on Fuzzy Theory and Aplications, Springer, Germany.

- Kumara, S \& Aggarwal, M. (2012). intelligence and achievement as the correlates of college of eduction faculty in the pennsy Ivania state 
system of higher eduction ,ph.D , Dissertation, Indiana, university of Pennsylvania Lawrence, A., Xavier,A.(2013): lateral thinking of prospective teacher: light house, $\operatorname{vol}(1 \mathrm{v}), \mathrm{no}(41), \mathrm{pp} 72-78$.

- Labibah N, Susanto, and Yuliati, N(2017). The Analyzing of Student's Lateral Thinking Process in Solving Open Ended Probem of Rectangular and Square Material, The International Journal of Social Sciences and Humanities Invention 4(8): 3840-3843, 2017 ,DOI: 10.18535/ijsshi/v4i8.25 ICV 2015: 45.28

- Madhavaiah, U \& Ram, M. V. Raghu (2016). Enhancing Lateral Thinking in Engineering Graduates (Indian Context).International Journal of Scientific \& Engineering Research, 346-350.

- Rajjan Shinghal (2013). Introduction to fuzzy logic, PHI learning private Limited, Delhi.

- Richardson A.J.et (2003). The Use of Lateral Thinking in Finding Creative Conflict Resolutions, Bodman Longley.

- Sloane, P. (2003). The leader's guide to lateral thinking skills : powerful problem solving techniques to ignite your team's potential. London; Sterling, VA: Kogan Page

- Zadeh, L.A (1988). Fuzzy Logic ,In, Sanchez-sinencio, E\&Lau,c(eds).,Artificial Neural Networks: paradigm ,Aplications .And Hard war Implementation, IEEEpress, Inc.,New York,1992

- Zadeh, L.A (1965).Fuzzy Sets, In: Yager, R., et al(eds),Fuzzy Sets and Aplications : Selected Papers By Zadeh,p.29-44

- Young-Jou Lai \& Ching-lai Hwang (1992). Fuzzy Mathematical Programming, Methods and Aplications, Springer-veriag, Germany 